\title{
Precipitation Parameterization in a Simulated Mei-Yu Front
}

\author{
Ming-Jen Yang ${ }^{1}{ }^{*}$, Fang-Ching Chien ${ }^{2}$ and Ming-Dean Cheng ${ }^{3}$ \\ (Manuscript received 7 January 1999, in final form 15 November 1999)
}

\begin{abstract}
Observational and numerical studies have consistently shown the importance of latent heat release associated with frontal precipitation in the development of a Mei-Yu front. However, a systematic evaluation of precipitation parameterization in the simulation of a Mei-Yu front has been rare in the literature. In order to enhance our understanding on precipitation parameterization of Mei-Yu fronts, this study conducts numerical experiments to evaluate the performance of subgrid-scale cumulus schemes and resolvable-scale microphysics schemes to simulate the Mei-Yu frontal system on 4-5 June 1998 at grid resolutions of $45 \mathrm{~km}$ and $15 \mathrm{~km}$, using the Penn State/NCAR mesoscale model MM5. Principal findings are summarized here.

- The horizontal extent and intensity of precipitation, the partitioning of precipitation into grid-resolvable and subgrid-scale portions, the vertical thermodynamic profile in the precipitation region and the embedded mesoscale structure are extremely sensitive to the choice of cumulus parameterization schemes. This is true for both the 45 - and $15-\mathrm{km}$ grids.

- The partitioning of precipitation into subgrid scale and resolvable scale is sensitive to the particular cumulus parameterization that is used in the model, but it is nearly the same on both the 45 - and $15-\mathrm{km}$ grids for a given cumulus parameterization.

- The detailed ice-phase microphysical processes do not have a significant impact on the rainfall pattern on either the 45- and 15-km grids. However, the inclusion of cloud ice-snow-graupel microphysical processes increases the total surface precipitation amount by $30 \%$ compared to the amount with only warm rain processes.

- Variations in the subgrid-scale cumulus parameterization have a much larger impact on the distribution and amount of Mei-Yu frontal precipita-
\end{abstract}

${ }^{1}$ Department of Atmospheric Sciences, Chinese Culture University, Taipei, Taiwan, ROC

${ }^{2}$ Department of Earth Sciences, National Taiwan Normal University, Taipei, Taiwan, ROC

${ }^{3}$ Research and Development Center, Central Weather Bureau, Taipei, Taiwan, ROC

${ }^{\star}$ Corresponding author address: Dr. Min-Jen Yang, Department of Atmospheric Sciences, Chinese Culture University, 55 Hua Kang Road, Taipei, Taiwan, 111, ROC

Email: mingjen@twister.atmos.pccu.edu.tw 


\title{
tion than do variations in the resolvable-scale microphysics parameteriza- tion at mesoscale grid resolutions of $10-50 \mathrm{~km}$.
}

\author{
(Key words: Quantitative Precipitation Forecast, Numerical Simulation, \\ Cumulus Parameterization, Microphysics Parameterization)
}

\section{INTRODUCTION}

Precipitation is one of the most difficult parameters to forecast in numerical weather prediction. Despite the substantial reductions in forecast errors for winds, temperatures, sea level pressures and geopotential heights due to improvements in numerical modeling over the past decade, progress in precipitation prediction has been very slow (Olson et al., 1995). Difficulties in precipitation prediction exist in at least three areas. First, our understanding of precipitation phenomena is still quite limited. Second, data deficiencies often limit the accuracy of a model's initial conditions, which are crucial in the prediction of precipitating systems. The third difficulty is attributed to the improper representation of both explicit-scale and subgridscale precipitation processes in a numerical model. The representation of subgrid-scale convective processes is called cumulus parameterization, and its challenge and complexity have been recognized for many years (Emanuel and Raymond 1993).

A wide variety of cumulus parameterization schemes (CPSs) has been developed and incorporated into numerical models (e.g., Kuo 1974; Arakawa and Schubert 1974; Anthes 1977; Fritsch and Chappell 1980; Betts and Miller 1986; Kain and Fritsch 1993; Grell 1993). Microphysical parameterizations of varying degrees of sophistication have been developed to treat the cloud precipitation processes explicitly on the resolvable scale. Successful applications in mesoscale models have been reported in both semi-prognostic tests (Grell et al., 1991) and fully prognostic tests (Zhang et al., 1989; Kuo et al., 1996). However, most of these studies have evaluated one or several CPSs for convective phenomena in specific synoptic environments, mainly midlatitude cases in the continental United States.

Kuo et al. (1996) assessed the performance of various subgrid-scale cumulus schemes and resolvable-scale microphysics schemes in the simulation of an explosive oceanic cyclone, using the Penn State/NCAR mesoscale model MM5. Wang and Seaman (1997) presented a comparison of cumulus parameterizations of six precipitation events for both cold and warm seasons over the continental United States, also using the MM5 model. However, a systematic evaluation of the cumulus schemes in the simulation of Mei-Yu frontal systems has been rare in the literature. Because of the lack of a universal conceptual framework for cumulus parameterization (Arakawa 1993), the applicability of any CPS is not obvious when it is applied in an environment different from that where it was originally tested.

The Mei-Yu, which literally means plum rain in Chinese, is a climate regime characterized by the frequent occurrence of mesoscale convective systems during the seasonal transition period when summer monsoon advances stepwise northwardly through southeast Asia. In Japan this phenomenon is referred to as the Baiu. The climatological Mei-Yu season in the Taiwan area lasts from mid May to mid June and coincides with a local maximum in the 
seasonal precipitation distribution.

Mei-Yu fronts are quasi-stationary and often produce long but narrow cloud bands that are clearly visible in satellite imagery. They first appear in southern China during May, move northward over Taiwan and southeastern China from mid May to mid June, then migrate farther north to the Yangtze River region as well as Japan during June and July. The climatological and synoptic characteristics of Mei-Yu fronts have been extensively studied by meteorologists in Taiwan, China and Japan (e.g., Chen and Chi 1980; Chen 1983; Matsumoto et al., 1971; Ninomiya 1984). The frequency of surface frontogenesis during Taiwan's Mei-Yu season indicates that an east-west belt north of Taiwan is the primary location for frontogenesis (Chen and Chi 1980). On average, 4-5 frontal systems affect Taiwan during the Mei-Yu season (Chen 1995). A Mei-Yu front is characterized by a strong moisture gradient and horizontal wind shear rather than a strong temperature gradient as observed in a typical polar front (Akiyama 1973; Kato 1985). This is true especially near the end of the Mei-Yu season (Chen and Chang 1980).

The Mei-Yu fronts in the vicinity of Taiwan are relatively shallow (cold air depth $\sim 1 \mathrm{~km}$ ) and are usually distorted by the topography of Taiwan and the coastal mountains in southeastern China (Chen et al., 1989; Chen 1993; Chen and Hui 1992). Vigorous convection and organized mesoscale convective systems, producing heavy rainfall, are of ten embedded within a Mei-Yu front (Wang et al., 1990; Kuo and Chen 1990). The deep convection and associated latent heat release within mesoscale convective systems play an important role in the maintenance of the frontogenetical process in a Mei-Yu front (Kuo and Anthes 1982; Hsu and Sun 1994).

A low-level jet (LLJ) with wind speed exceeding $12.5 \mathrm{~m} \mathrm{~s}^{-1}$ at 850 and $700 \mathrm{hPa}$ is commonly observed in association with a Mei-Yu front and often precedes heavy rainfall events over Taiwan by as much as 12 hours (Chen and Yu 1988). The LLJ not only transports moisture into the frontal zone but also destabilzes the lower atmosphere, thus providing a favorable environment for the development of heavy precipitation. The LLJ is frequently observed on the warm side of a Mei-Yu front (Chen 1977, 1983) and is highly ageostropic (Matsumoto et al., 1971). Hsu and Sun (1994) successfully simulated an LLJ and demonstrated that large-scale latent heat release and secondary circulation are the two primary mechanisms that maintain the LLJ. Hence, an adequate treatment of convection and precipitation processes which are responsible for the release of latent heat is crucial for the success of a numerical simulation of a Mei-Yu front.

In this study, we first examine how well different CPSs perform in a mesoscale model under a given Mei-Yu frontal synoptic condition. Second, we investigate whether increased model resolution improves quantitative precipitation forecasts and if so, by how much. Third, for cumulus schemes designed originally for large-scale numerical models, we identify the characteristic problems encountered in mesoscale applications. In other words, we determine whether CPSs behave differently at different grid resolutions in the range of $10-50 \mathrm{~km}$.

We perform a sensitivity study of the development of a Mei-Yu front and its associated precipitation characteristics to various precipitation parameterization schemes. A series of numerical simulations of the Mei-Yu frontal system on 4-5 June 1998 are conducted using the Penn State/NCAR nonhydrostatic mesoscale model MM5 at grid resolutions of $45 \mathrm{~km}$ and 15 
$\mathrm{km}$. The objective of this study is to assess the performance of various subgrid-scale cumulus parameterization and explicit-scale microphysics schemes in the simulation of a Mei-Yu frontal system. We are particularly interested in understanding how different schemes affect the development of a Mei-Yu front, the precipitation distribution and total amount as well as the simulated mesoscale structures.

\section{BRIEF SYNOPSIS OF THE OBSERVED MEI-YU FRONT}

During 1-10 June 1998, heavy rainfall occurred over the southwestern plain and mountains of Taiwan. In that period, the Central Weather Bureau (CWB) issued heavy rainfall warnings for southwestern Taiwan for 10 consecutive days (1-10 June). This 10-day flooding episode induced landslides of various scales and resulted in property and agriculture losses totalling approximately 1 billion NT dollars (approximately 30 million US dollars). The synoptic condition was characterized by the passage of a quasi-stationary Mei-Yu front. During this period, a deep trough of northeast-southwest orientation developed at upper levels (500$200 \mathrm{hPa}$ ) over the east coast of China. Although the flooding events lasted from 1 to 10 June 1998 , this paper concentrates on the Mei-Yu front and its associated mesoscale precipitation that occurred during the 4-5 June 1998 period.

The surface analysis at 0000 UTC 5 June 1998 is shown in Fig. 1. Ahead of the front, the wind was mainly southwesterly. Behind the front, the wind varied from northeasterly to northerly. The temperature gradient in the vicinity of the surface front was weak and characterized by a moderate moisture gradient.

As illustrated by the IR imagery for 0000 UTC 5 June (Fig. 2), a frontal cloud band along the Mei-Yu front extended from Japan to the Luzon Strait (north of the Philippines) to Hainan Island. In particular, there was organized deep convection associated with three mesoscale convective systems (MCSs) in the northern South China Sea, extending westward from the Luzon Strait, Dongsha Island to Hainan Island.

\section{MODEL AND EXPERIMENT DESIGN}

The numerical model used in this study is the Penn State/NCAR nonhydrostatic model MM5 (Grell et al., 1994) Version 2.7. The MM5 is a three-dimensional, limited-area, primitive-equation, nested-grid model with a terrain following $\sigma$ (non-dimensional pressure) vertical coordinate. The physical parameterizations of the model include the Blackadar (1979) planetary boundary layer scheme with surface energy flux and friction, the short-wave and long-wave radiation schemes with interaction between clear sky and clouds, the resolvablescale microphysics parameterization and the subgrid-scale cumulus parameterization. The model configuration includes a coarse mesh of 45-km horizontal resolution and a fine mesh of $15-\mathrm{km}$ horizontal resolution (Fig. 3). Domain dimensions for each mesh are $81 \times 71$ for the coarse mesh and $91 \times 91$ for the fine mesh. There are $27 \sigma$ levels in the vertical (surface pressure level to $50 \mathrm{hPa}$ ): $1.00,0.99,0.98,0.97,0.96,0.95,0.94,0.93,0.90,0.89,0.85,0.80$, $0.75,0.70,0.65,0.60,0.55,0.50,0.45,0.35,0.30,0.25,0.20,0.15,0.10$ and 0.05 . The MM5 


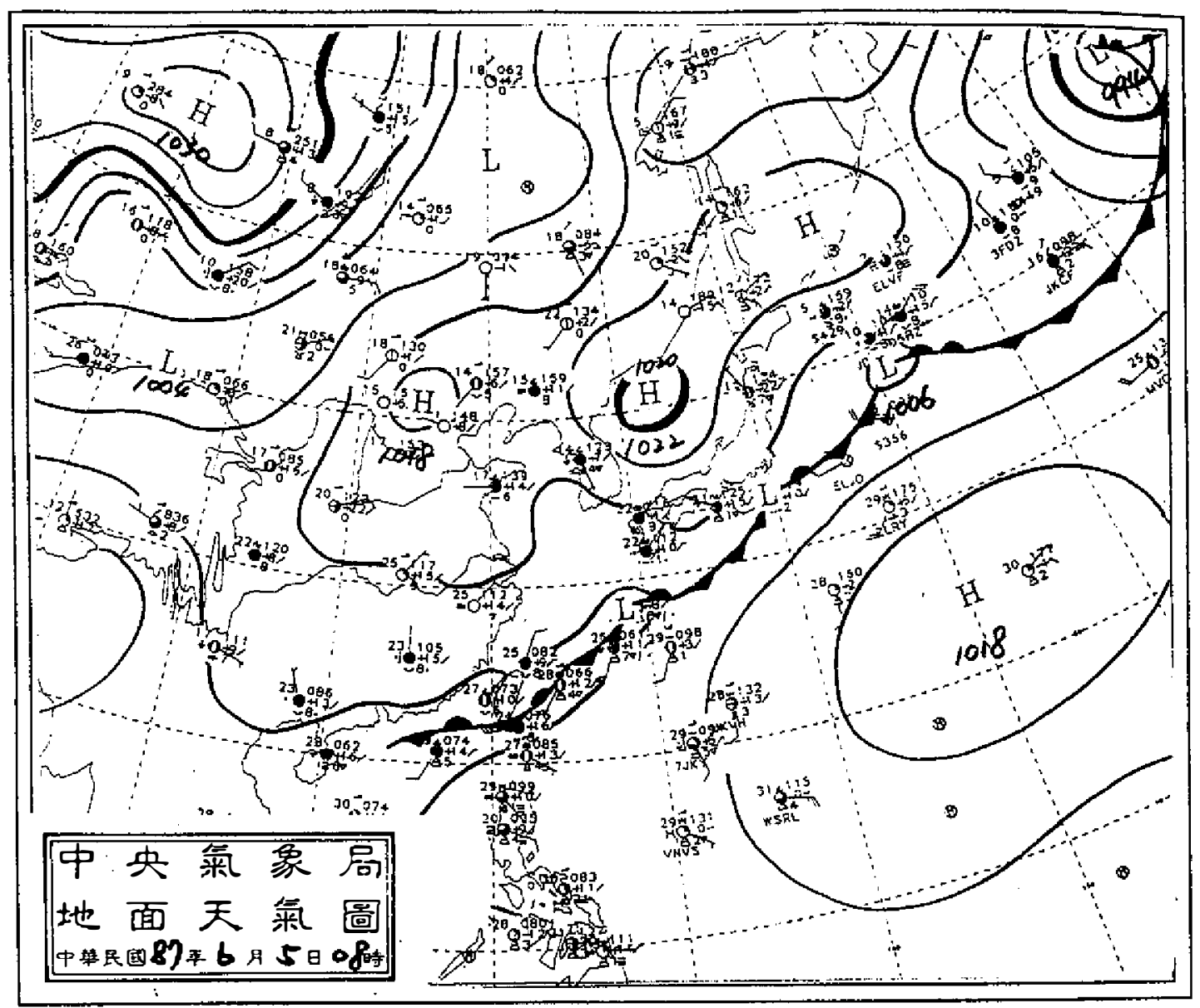

Fig. 1. Surface analysis at 0000 UTC 5 June 1998 (isobars in solid lines). Abbreviated plotting symbols follow usual convention with wind in knots (full barb, 10 knots), pressure in millibars (tens and unit digits) and temperature and dewpoint in degrees Celsisus.

model is initialized at 0000 UTC 4 June 1998 and the forecast length of each MM5 run is 36 hours (i.e., simulation ends at 1200 UTC 5 June 1998). The initial condition is provided by the analysis field from the Central Weather Bureau Global Forecast System (CWBGFS; Liu et al., 1997), while the boundary condition is provided by the CWBGFS forecast. The sea surface temperature (SST) field is also provided by CWBGFS analysis and is held constant throughout the simulations.

Table 1 lists the numerical experiments conducted in this study. The sensitivity experiments of cumulus parameterizations include the schemes of Betts-Miller (1993), and Grell (1993), Kain-Fritach (1993) and Kuo (1974). The sensitivity tests of microphysics parameterizations include the schemes of Warm Rain (Hsie et al., 1984; Kessler 1969), Simple 


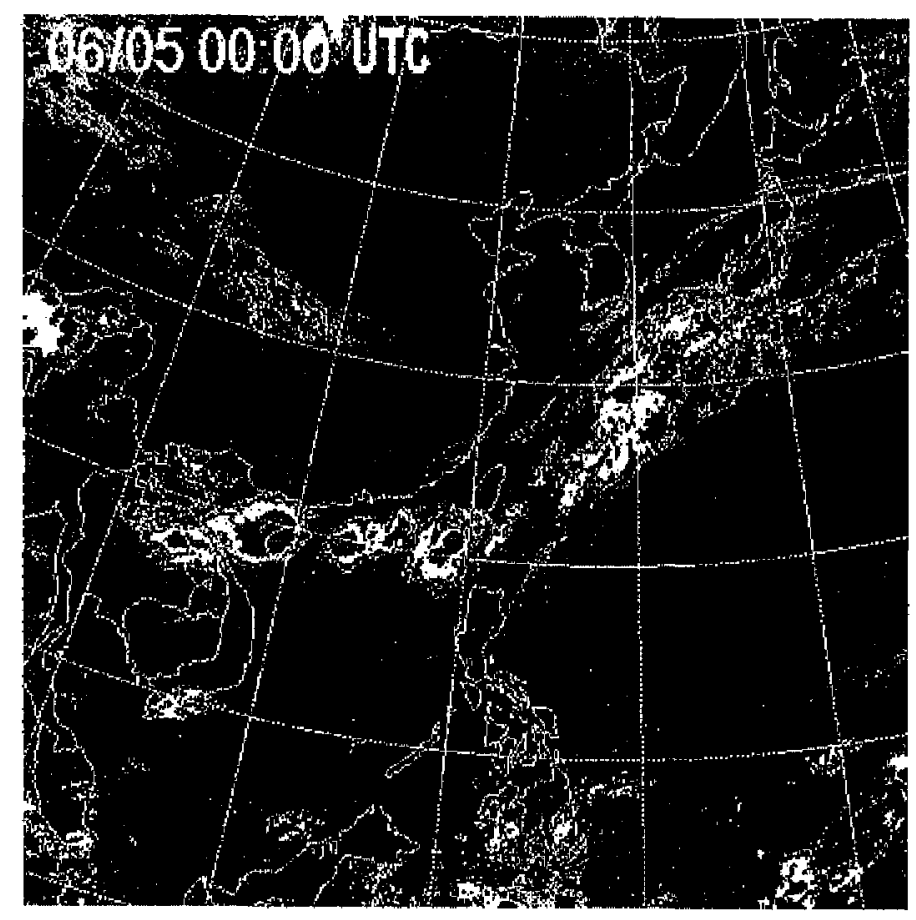

Fig. 2. IR satellite image at 0000 UTC 5 June 1998.

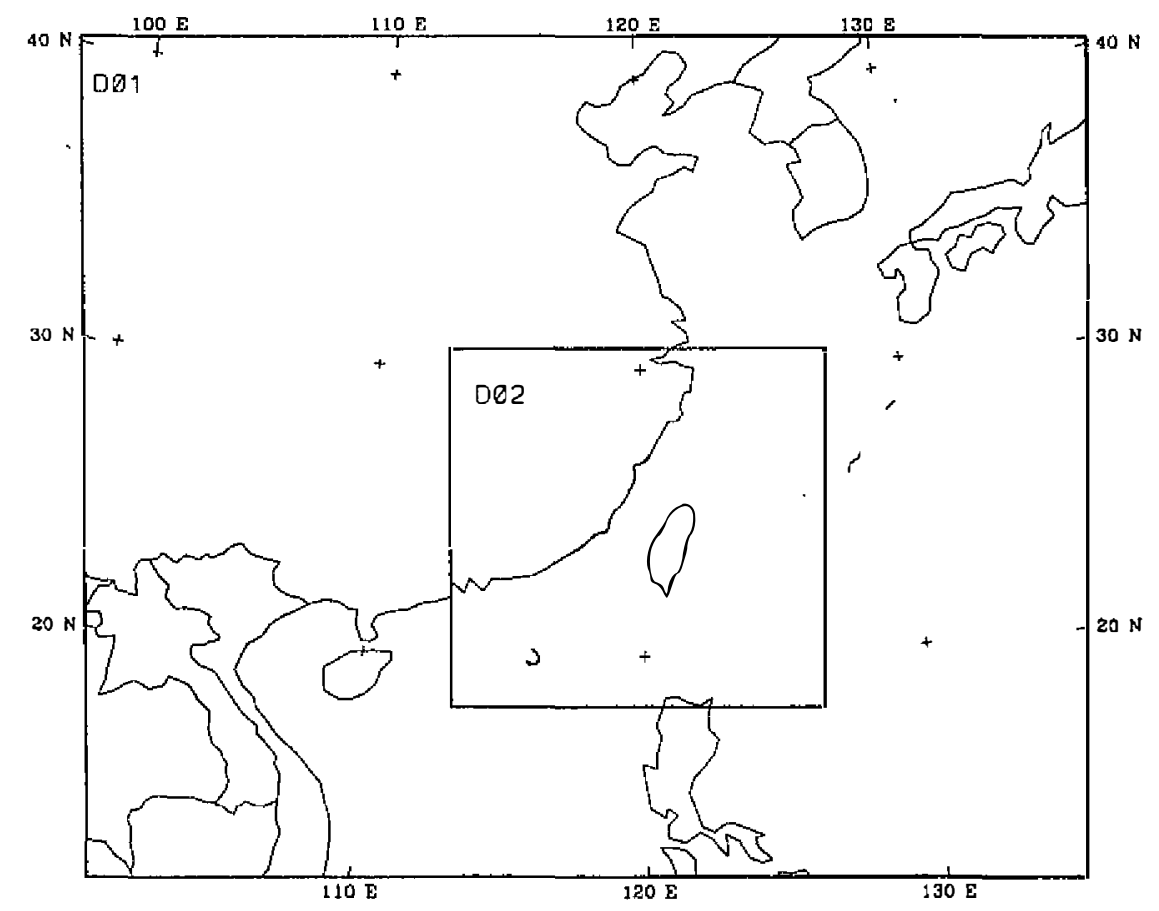

Fig. 3. Computational domains for the $45-\mathrm{km}$ and $15-\mathrm{km}$ grid sizes. 
Table 1. Summary of numerical experiments.

\begin{tabular}{lll}
\hline Name & Cumulus parameterization & Microphysics parameterization \\
\hline
\end{tabular}

Set A: Test of cumulus parameterization on the $45-\mathrm{km} / 15-\mathrm{km}$ nested grid

$\begin{array}{lll}\text { BM } & \text { Betts-Miller } & \text { Simple Ice } \\ \text { GR } & \text { Grell } & \text { Simple Ice } \\ \text { KF } & \text { Kain-Fritsch } & \text { Simple Ice } \\ \text { AK } & \text { Anthes-Kuo } & \text { Simple Ice }\end{array}$

Set B: Test of microphysics parameterization on the $45-\mathrm{km} / 15-\mathrm{km}$ nested grid

$\begin{array}{lll}\text { WR } & \text { Kain-Fritsch } & \text { Warm Rain } \\ \text { SI* }^{*} & \text { Kain-Fristch } & \text { Simple Ice } \\ \text { MP } & \text { Kain-Fritsch } & \text { Mixed Phase } \\ \text { GG } & \text { Kain-Fritsch } & \text { Goddarrd Graupel }\end{array}$

*: The KF experiment and SI experiment are the same since they use the same options of cumulus and microphysics parameterizations.

Ice (Dudhia 1989), Mixed Phase (Reisner et al., 1998) and Goddard Graupel (Tao and Simpson 1993).

It should be noted that it would be inappropriate to attribute all the errors in the precipitation forecast solely to a cumulus or microphysics scheme in this full-prognostic experiment framework (Wang and Seaman 1997). Inaccurracies in other physics parameterization schemes and uncertainities in the initial conditions could also contribute to precipitation forecast errors. Because of this complexity, it is important that each numerical experiment use the same model setting, identical physics (except the physical scheme being testing) as a common framework and the same initial conditions. This experiment design simplifies the interpretation of the results and facilitates forecast intercomparisons.

\section{CUMULUS EXPERIMENT}

\section{a. Precipitation verification}

There may be little doubt that to simulate convection phenomena a CPS is needed for a numerical model with a grid resolution of $45 \mathrm{~km}$. However, it is not as clear-cut whether a CPS is needed at a grid resolution of $15 \mathrm{~km}$ or whether any of the commonly used CPSs are applicable at that scale (Kuo et al., 1996; Wang and Seaman 1997). None of these CPSs have been designed specifically for a $15-\mathrm{km}$ grid. In fact, only the Grell scheme and Kain-Fritsch 
scheme were developed and tested for resolutions as small as $20-25 \mathrm{~km}$, while the Kuo scheme and Betts-Miller scheme were originally applied at much coarser resolutions. Therefore, the implementation of these CPSs at a $15-\mathrm{km}$ grid requires further evaluation. With the increase in computational power, the real-data operation of mesoscale modeling now advances to the $10-15 \mathrm{~km}$ grid scale; hence, it is important to objectively assess the performance of a variety of cumulus schemes on the $10-15 \mathrm{~km}$ grid scale to facilitate future model design.

All CPSs have disposable parameters that may be "tuned" to enhance their performance for a given type of convective system, for example a Mei-Yu frontal convection. Thus, the performance of these CPSs for the convection and precipitation associated with a Mei-Yu front needs to be examined.

In this set of cumulus experiments, the Simple Ice scheme (Dudhia 1989) is used for microphysics parameterization on both the $45-\mathrm{km}$ and $15-\mathrm{km}$ grids. Figure 4 shows the $6-\mathrm{h}$ accumulated total (parameterized and resolved) rainfall (1800 UTC 4 June to 0000 UTC 5 June 1998) on the $45-\mathrm{km}$ grid as predicted by each cumulus experiment. Comparing Fig. 2 and Fig. 4, it is recognized that the Mei-Yu frontal rainfalls are produced in all cumulus experiments, although their locations are farther north compared with satellite observations. Note that these precipitation forecast errors do not solely result from the chosen cumulus scheme. Some errors may be due to a poor representation of the initial moisture field, especially over the data-sparse South China Sea area. Other errors may be related to the coupling of cumulus schemes with other physical parameterization schemes and the improper representation of sharp gradients associated with water substance in numerical techniques.

The rainfall prediction in the Grell (GR) experiment (Fig, 4b) is in good agreement with satellite observations in terms of the Mei-Yu frontal precipitation pattern and organization. The Betts-Miller (BM) experiment (Fig. 4a) has reasonable performance with regard to Mei$\mathrm{Yu}$ frontal precipitation and is similar to that of the GR experiment, except that it over-predicts the rainfall area over the northern South China Sea. The Kain-Fritsch (KF) experiment (Fig. 4c) shows similar frontal precipitation forecast results to those of the GR and BM experiments, but the rainfall area is too widespread and the rainfall intensity is too weak, especially over the subtropical open ocean. The rainfall forecast in the Anthes-Kuo (AK) experiment (Fig. 4d) is not as good as that in other experiments since it fails to represent the organized MCSs over the northern South China Sea, and it underestimates the frontal precipitation.

Figure 5 illustrates the 6-h rainfall forecasts of these four cumulus experiments on the 15$\mathrm{km}$ grid for the same time period. It is clear from Fig. 5 that more detailed mesoscale structures on precipitation and pressure fields can be found with the increase in grid resolution. Therefore, the simulated rainfall pattern and intensity have more pronounced variations among each cumulus experiment on the $15-\mathrm{km}$ grid.

\section{b. Parameterized versus resolved precipitation}

As is typical in the evaluation of an operational modeling system, the comparisons presented thus far have focused on total precipitation (Figs. 4 and 5) without regard to whether the rainfall is produced through resolvable-scale processes or through parameterized processes. In a numerical model that uses both subgrid-scale and grid-scale precipitation schemes, a 
a) Betts-Miller

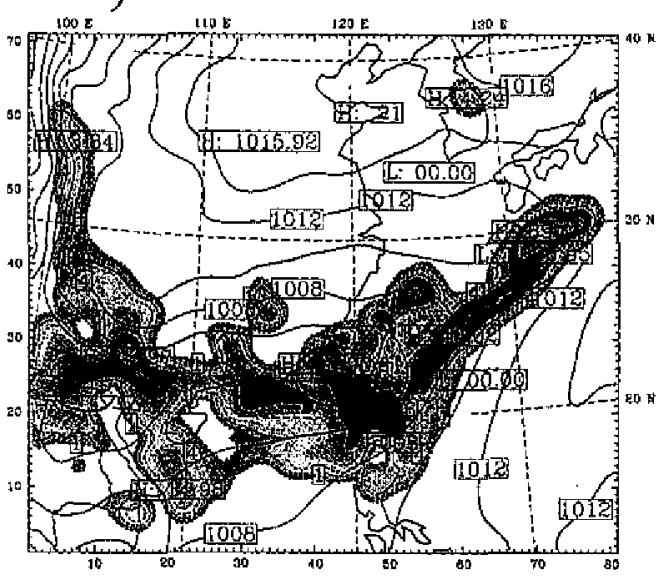

c) Kain-Fritsch

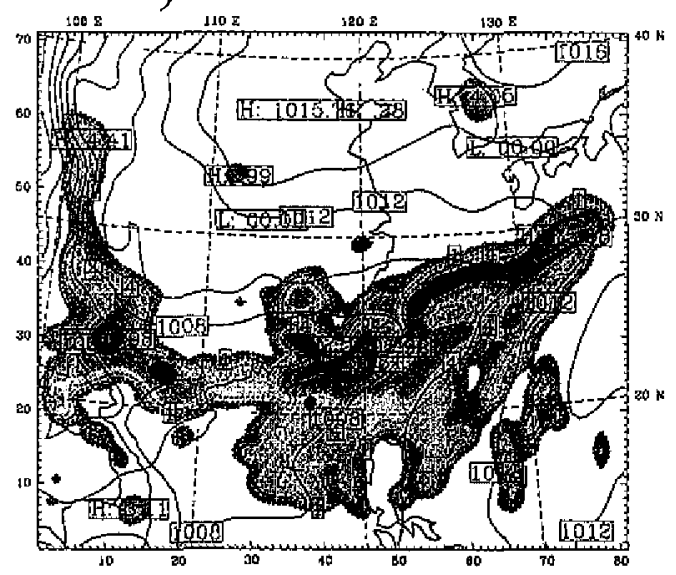

b) Grell

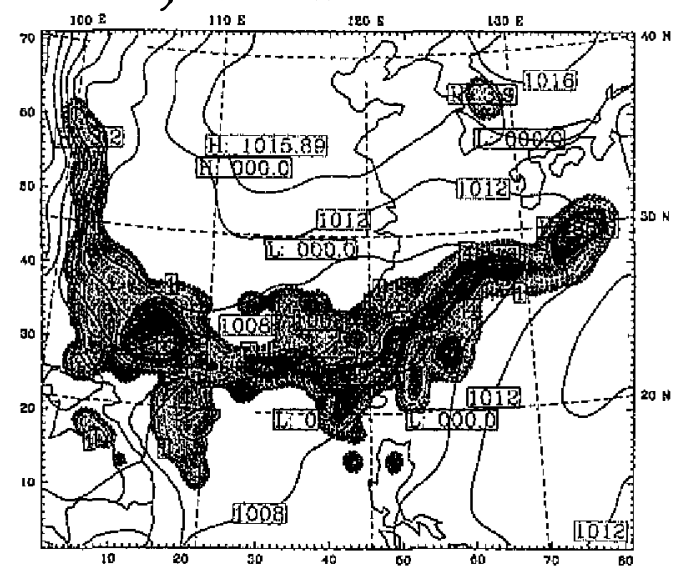

d) Anthes-Kuo

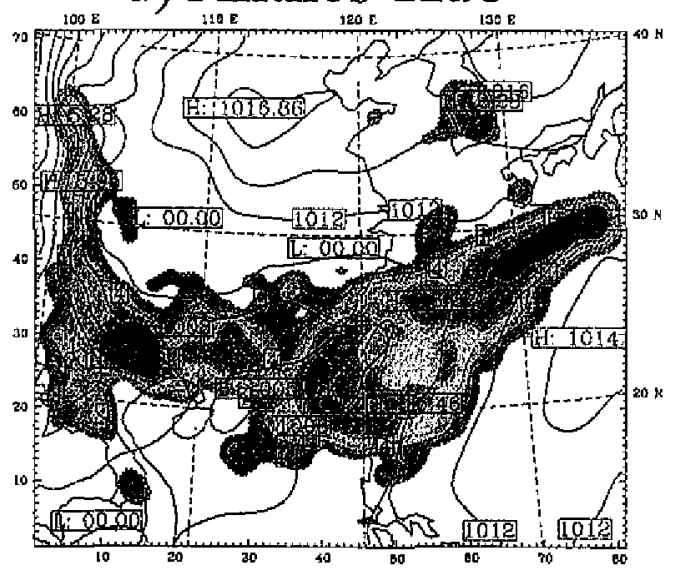

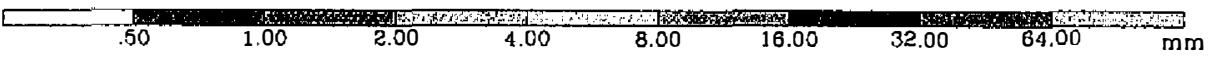

Fig. 4. Simulated sea-level pressure with contours of $2 \mathrm{hPa}$ for various cumulus parameterizations on the $45-\mathrm{km}$ grid at 24-h forecast time (valid at 0000 UTC 5 June 1998): (a) Betts-Miller, (b) Grell, (c) Kain-Fritsch, and (d) Anthes-Kuo schemes. Shading indicates 6-hourly (1800 UTC 4 June to 0000 UTC 5 June) accumulated rainfall in units of $\mathrm{mm}$. Solid dot is the location of Dongsha sounding in Figs. 11 and 12.

reasonable partition between parameterized and resolved rainfall is very important to produce realistic simulations of precipitation events and to prevent the occurrence of excessive static instability (Kuo et al., 1996). This is because the subgrid-scale cumulus scheme represents a more rapid upward transport of heat and moisture, and hence it can stabilize a vertical grid column faster than the grid-scale microphysics scheme. 
a) Betts-Miller

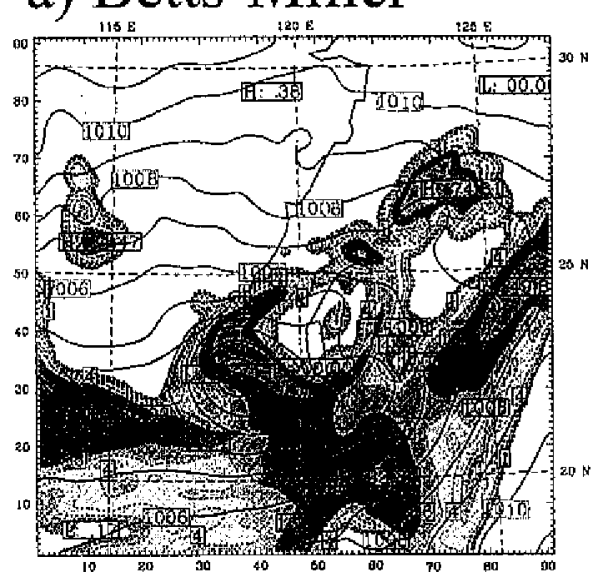

c) Kain-Fritsch

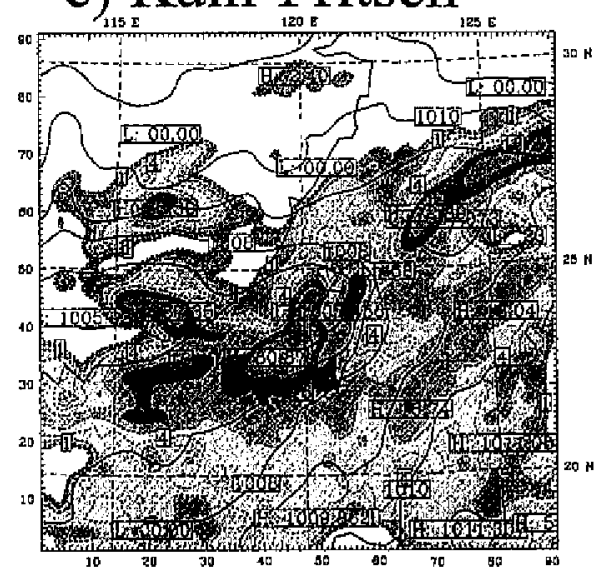

b) Grell

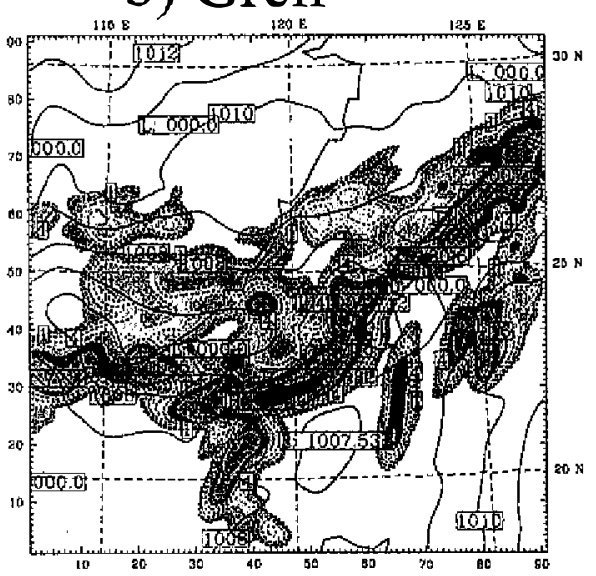

d) Anthes-Kuo

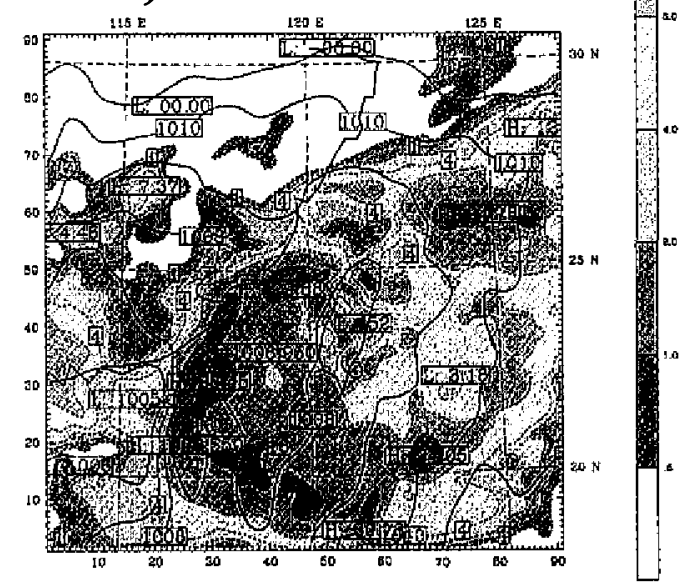

Fig. 5. Simulated sea-level pressure with contours of $1 \mathrm{hPa}$ for various cumulus parameterizations on the $15-\mathrm{km}$ grid at $24-\mathrm{h}$ forecast time (valid at 0000 UTC 5 June 1998): (a) Betts-Miller, (b) Grell, (c) Kain-Fritsch, and (d) Anthes-Kuo schemes. Shading indicates 6-hourly (1800 UTC 4 June to 0000 UTC 5 June) accumulated rainfall in units of $\mathrm{mm}$.

Figure 6 shows the horizontal distribution of 6-h (1800 UTC 4 June to 0000 UTC 5 June) accumulated parameterized (left column) and resolved (right column) rainfall predicted by various cumulus schemes on the $45-\mathrm{km}$ grid. The BM experiment produces widespread parameterized precipitation along the Mei-Yu front and over the Luzon Strait and northern South China Sea (Fig. 6a); the resolvable-scale precipitation (Fig. 6b), in this case, shows very few rainfall cores along the frontal boundary. The GR experiment produces considerably smaller amounts of parameterized precipitation along the Mei-Yu front than does the BM experiment (Fig. 6c), with rainfall amounts generally less than $8 \mathrm{~mm} / 6 \mathrm{~h}$. Very little parameterized pre- 
a) Betts-Miller (parameterized)

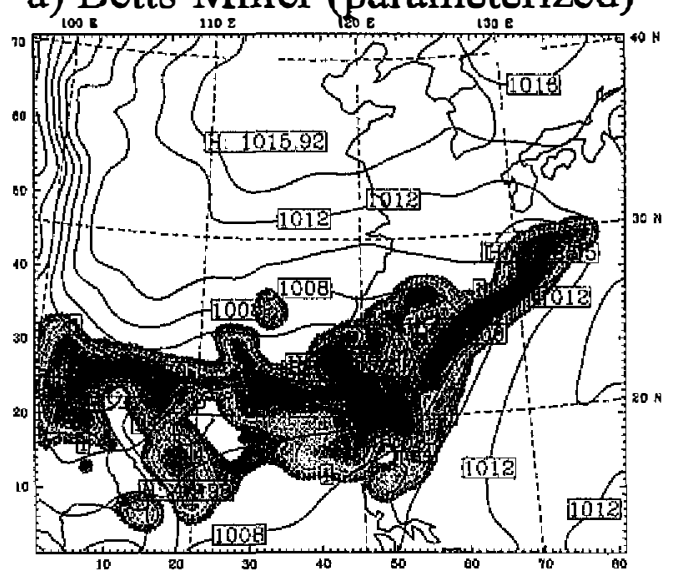

c) Grell (parameterized)

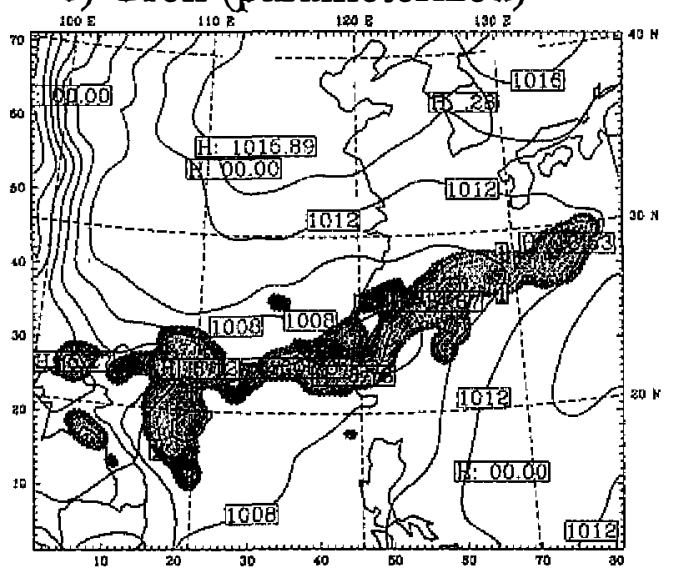

b) Betts-Miller (resolved)

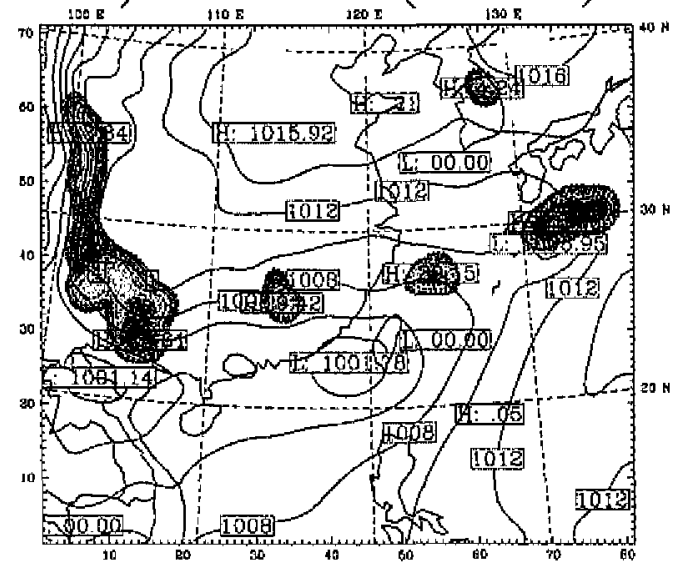

d) Grell (resolved)

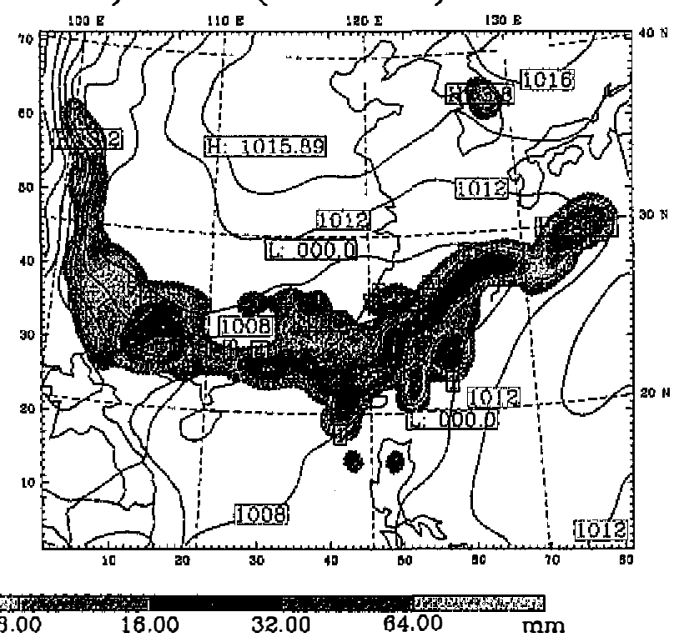

Fig. 6. Shading is the parameterized (left) and grid-resolved (right) 6-hourly ( 1800 UTC 4 June to 0000 UTC 5 June) accumulated rainfall (in $\mathrm{mm}$ ) by the (a) and (b) Betts-Miller, (c) and (d) Grell, (e) and (f) Kain-Fritsch, and $(\mathrm{g})$ and $(\mathrm{h})$ Anthes-Kuo schemes on the $45-\mathrm{km}$ grid. Solid lines are the sea-level pressure with contours of $2 \mathrm{hPa}$ at 0000UTC 5 June 1998.

cipitation is produced outside the frontal boundary. However, organized precipitation cells with a scale of six to eight grid points $(270-360 \mathrm{~km})$ are evident in the resolvable-scale precipitation for the GR experiment (Fig. 6d). One such cell near the Mei-Yu front has a maximum 6-hourly precipitation of $115 \mathrm{~mm}$. The $\mathrm{KF}$ experiment also produces widespread parameterized precipitation along the Mei-Yu front (Fig. 6e). Light precipitation is found ahead and behind the frontal boundary and also over the northern South China Sea. Resolvable-scale 
e) Kain-Fritsch (parameterized)

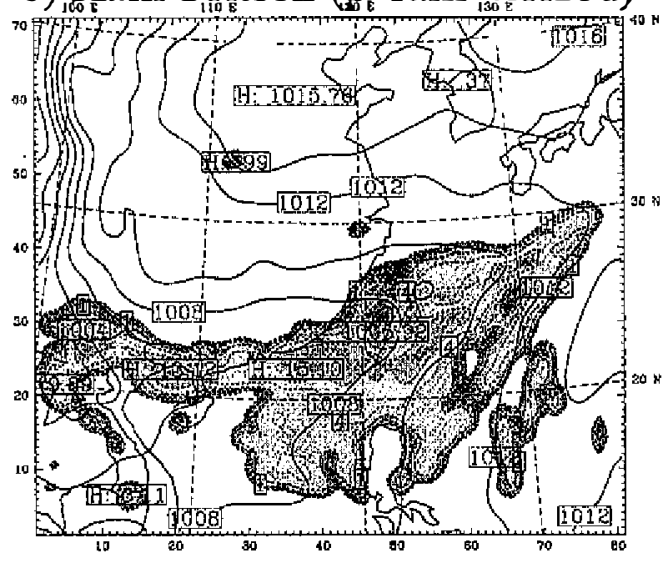

g) Anthes-Kuo (parameterized)

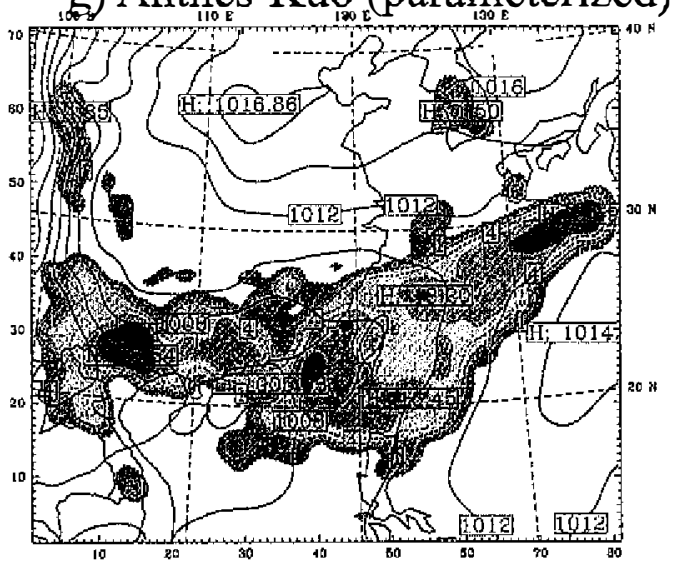

f) Kain-Fritsch (resolved)

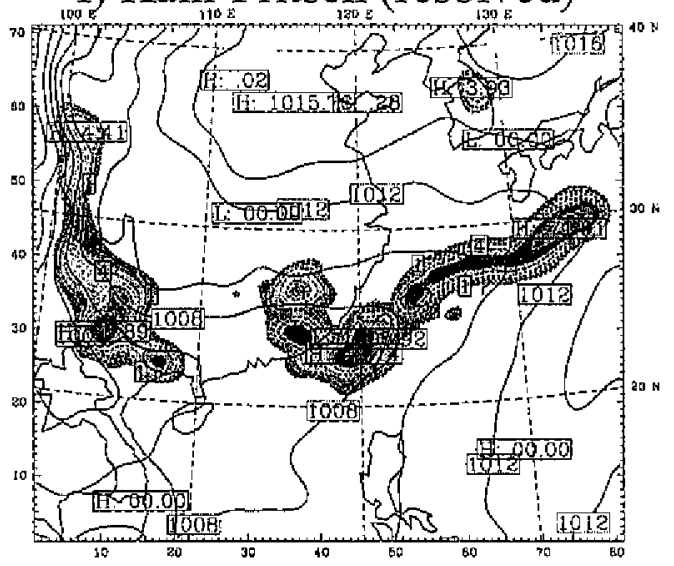

h) Anthes-Kuo (resolved)

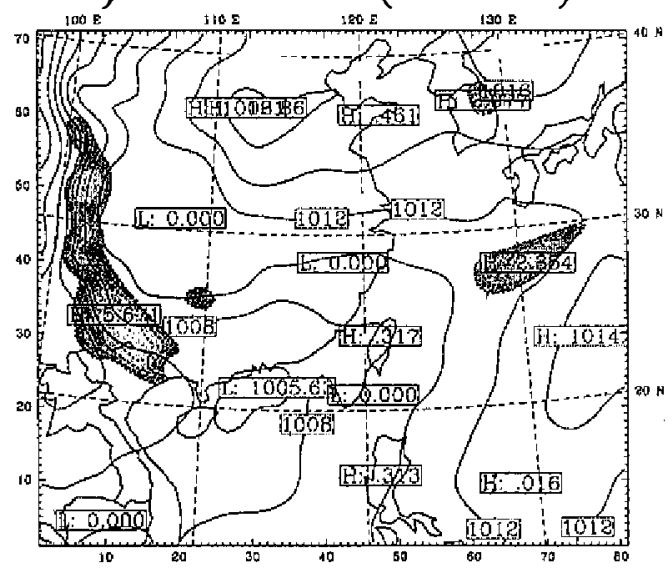

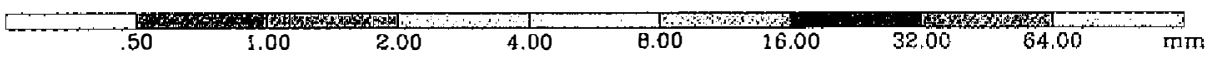

(Fig. 6. continued)

precipitation of stronger intensity and covering a smaller area is predicted along the frontal boundary (Fig. 6f). The AK experiment (Figs. 6g and 6h), in sharp contrast to the GR experiment, exhibits very little resolvable-scale rain but a large amount of parameterized rain. The parameterized precipitation produced by the $\mathrm{AK}$ experiment covers a larger area than does that by the other cumulus experiments (BM, GR, and $\mathrm{KF}$ ).

From the results presented above (Fig. 6), it is evident that for the simulated Mei-Yu frontal system there is a significant variation in the partitioning, intensity, and distribution of parameterized and resolved rainfall among the precipitation predictions using different cumulus schemes. Similar results are found in Kuo et al. (1996) in the simulation of an explosive oceanic cyclone. It should be noted that although this set of experiments uses the same precipitation parameterization on the resolvable scale (Simple Ice microphysics scheme), the re- 
solved precipitation pattern and amount differ widely. This suggests that the parameterized heat and moisture transports on the subgrid scale have significant influences on the temperature and moisture distributions on the explicit scale in each cumulus simulation. This, therefore, results in a different intensity and distribution of explicit-scale precipitation despite the use of the same microphysics scheme.

The evolution of the domain-average 6-hourly precipitation and its parameterized and resolvable-scale components on the $45-\mathrm{km}$ grid is shown in Figs. 7a-c. The total precipitation amount (Fig. 7a) increases steadily during the first 24 hours of simulation in all experiments. The Kain-Fritsch, Betts-Miller, and the Anthes-Kuo experiments are all quite effective in producing parameterized precipitation during the first 12 hours of the simulation (Fig. 7b). Throughout the forecast period ( 36 hours), large variations in the partitioning between parameterized and resolvable-scale precipitation are seen (Figs. $7 \mathrm{~b}$ and $7 \mathrm{c}$ ). The Betts-Miller experiment produces the largest amount of parameterized rainfall at nearly all hours. The Anthes-Kuo experiment produces slightly less but comparable amounts of parameterized precipitation. The Kain-Fritsch experiment produces even less parameterized rainfall (Fig. 7b). Relatively small amounts of parameterized rainfall are generated by the Grell experiment.

Resolvable-scale rainfall (Fig. 7c) also displays considerable variations among these experiments. The AK experiment yields the smallest amount of resolvable-scale rainfall, whereas the GR experiment yields the largest. Resolvable-scale precipitation of all four cumulus experiments increases substantially. This behavior indicates that as time increases, more and more grid points become saturated and more precipitation takes place on the grid-resolvable scale. The ratio of parameterized to total (parameterized and resolved) rainfall is illustrated in Fig. 7 d. The $50 \%$ intercept marks the time that precipitation changes from predominantly subgrid scale to predominantly resolvable scale. For the GR experiment, the crossover occurs between hour 6 and hour 12, and it occurs at hour 24 in the KF experiment. In the AK and BM experiments, as noted previously, parameterized precipitation predominates throughout the 36-h simulation period.

The reason that the Grell scheme produces so little parameterized precipitation is that the parameterized rainfall produced by the Grell scheme is strongly affected by the precipitation efficiency parameterization and an automatic shut-off switch which is turned on when the precipitation efficiency is too low (Kuo et al., 1996). Due to this design in the precipitation efficiency parameterization, it is found that this switch causes the scheme to shut off quickly, consequently forcing the resolvable-scale scheme to take over frequently, which then results in little parameterized precipitation. The lack of resolvable-scale precipitation in the AnthesKuo scheme is likely caused by the stong dependence on parameterized precipitation to moisture convergence (Kuo et al., 1996). In the Anthes-Kuo scheme, the amount of parameterized rainfall is proportional to the column-integrated moisture convergence with a coefficient (1$b$ ), in which the parameter $b$ is a function of the environmental relative humidity (see Appen$\operatorname{dix} \mathrm{A}$ for more details). When a precipitation system begins to evolve, the environment is close to saturation, and $b$ becomes very small. Then all the moisture supply through columnintegrated moisture convergence has to be condensed as parameterized precipitation, leaving little or no moisture for the resolvable-scale precipitation.

The evolution of the domain-average 6-hourly precipitation and its parameterized and 
a) Total Rain

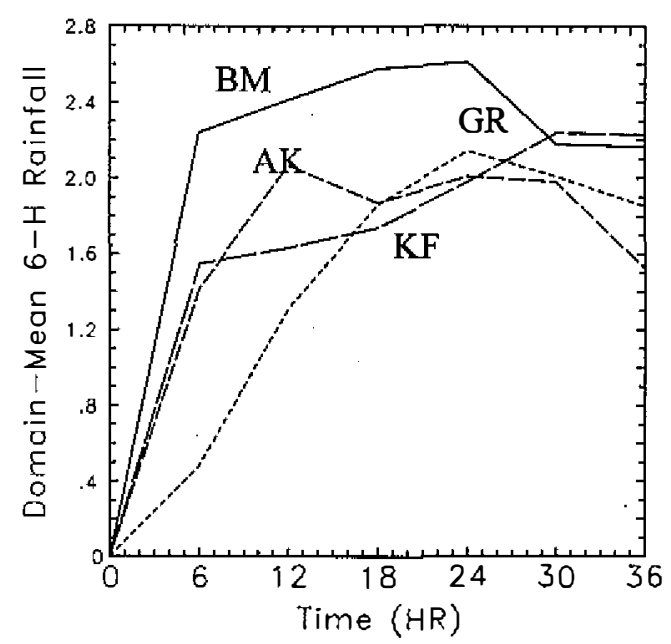

c) Resolved Rain

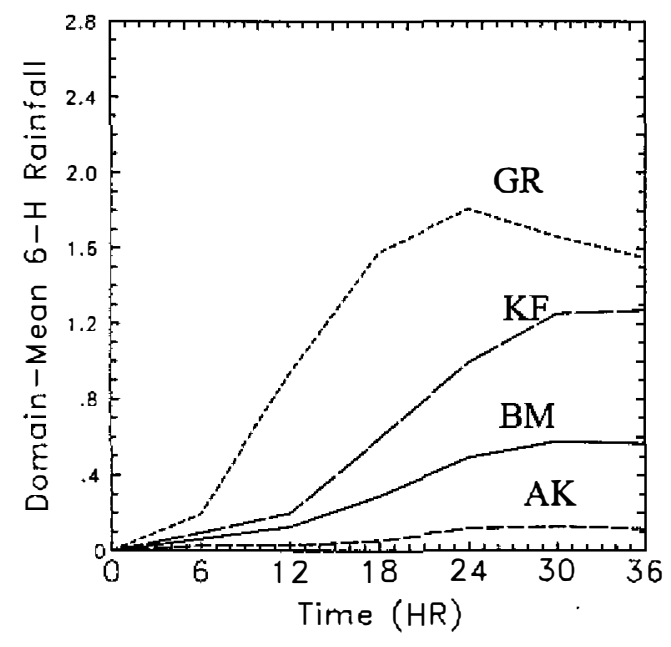

b) Parameterized Rain

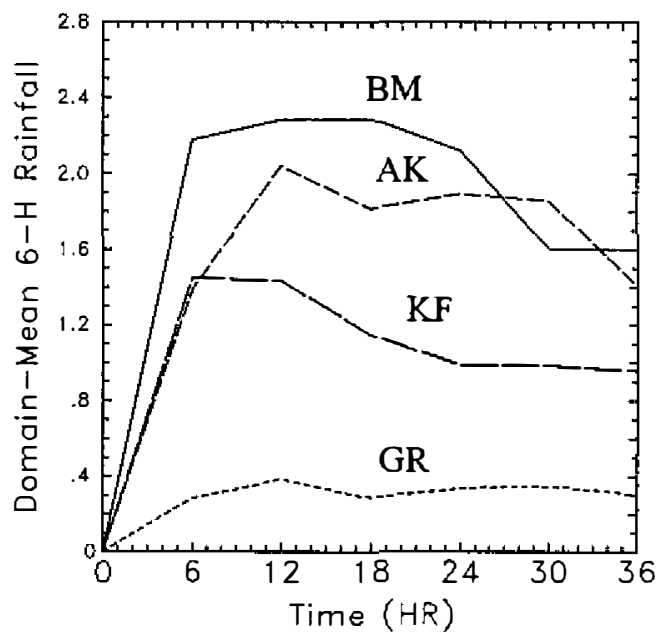

d) Parameterization Ratio

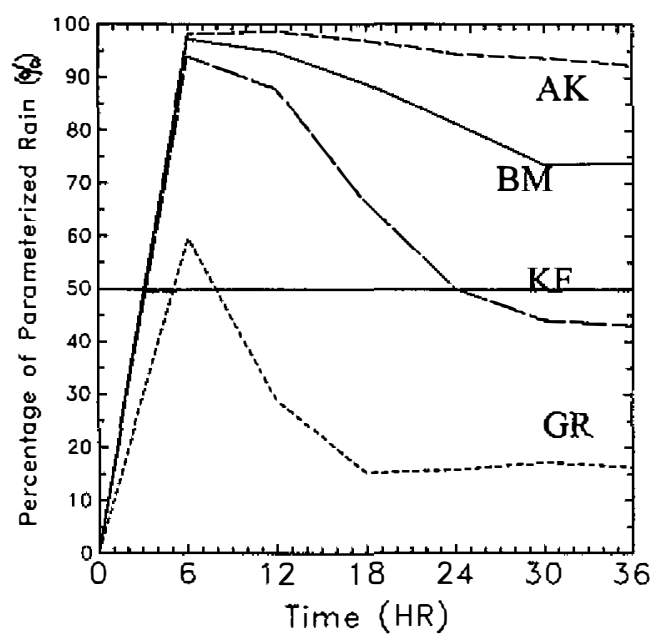

Fig. 7. (a) Domain-averaged 6-hourly total rainfall (in mm), (b) domain-averaged parameterized rainfall (in $\mathrm{mm}$ ), (c) domain-averaged resolved rainfall (in $\mathrm{mm}$ ), and (d) percentage of parameterized to total rainfall on the 45-km grid for the cumulus experiments. BM: Betts-Miller. GR: Grell. KF: Kain-Fritsch. AK: Anthes-Kuo.

resolvable-scale components on the $15-\mathrm{km}$ grid is presented in Fig. 8. The most striking feature in Figs. 7 and 8 is that the partitioning of model-predicted precipitation is vastly different from one scheme to another. At both 45-km (Fig. 7d) and 15-km (Fig. 8d) grid sizes, the AK experiment produces nearly all of the precipitation through parameterized convection 
a) Total Rain

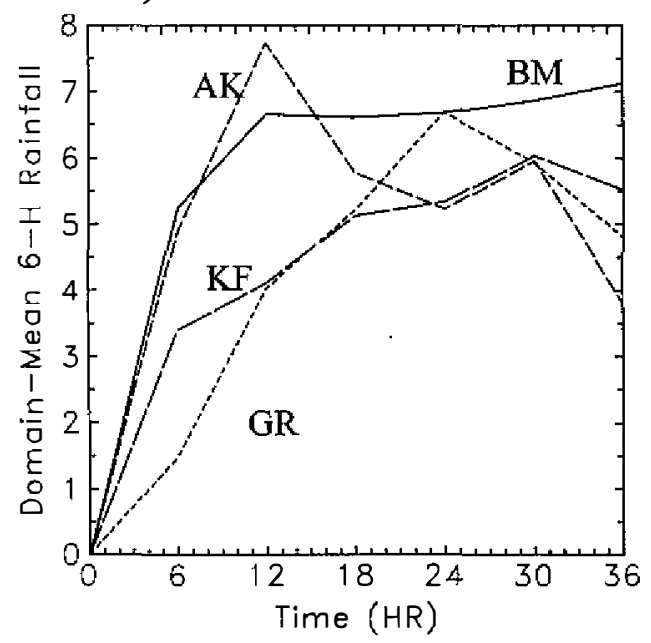

c) Resolved Rain

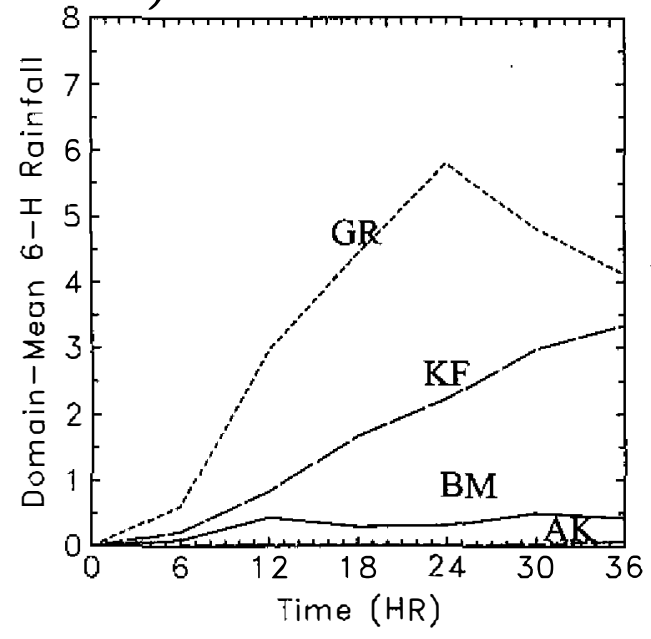

b) Parameterized Rain

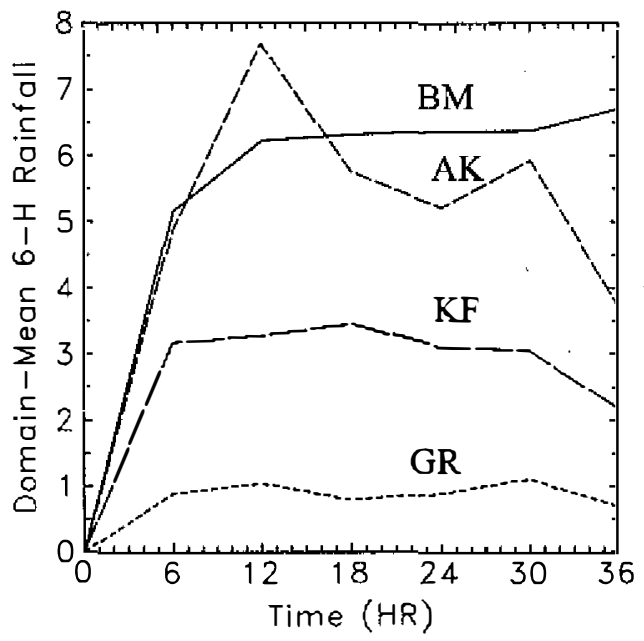

d) Parameterization Ratio

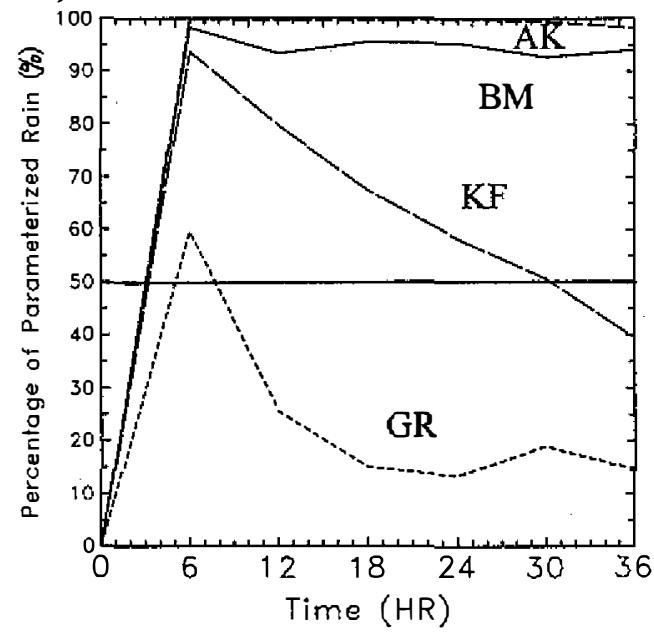

Fig. 8. (a) Domain-averaged 6-hourly total rainfall (in $\mathrm{mm}$ ), (b) domain-averaged parameterized rainfall (in $\mathrm{mm}$ ), (c) domain-averaged resolved rainfall (in $\mathrm{mm}$ ), and (d) percentage of parameterized to total rainfall on the 15-km grid for the cumulus experiment. BM: Betts-Miller. GR: Grell. KF: Kain-Fritsch. AK: Anthes-Kuo.

throughout the entire integration period. On the other hand, the GR experiment quickly switches from parameterized to resolved-scale dominance of precipitation around hour 12. The KF and BM experiments produce a rainfall partition somewhat between that of the GR and AK experiments. Overall, the ratio of parameterized to total precipitation remains roughly the same as grid size decreases, with the exception of the BM experiment. The change in the partitioning 
of the rainfall with respect to grid resolution for the Betts-Miller scheme may be explained in part by the choice of the relaxation time scale $\tau$ (Wang and Seaman 1997). In principle, $\tau$ should be reduced in the Betts-Miller scheme as the grid size is decreased so that appropriate subsaturation is maintained (Betts and Miller 1993). However, in this study the same value of $\tau=50 \mathrm{~min}$ is used at both $45-\mathrm{km}$ and $15-\mathrm{km}$ resolutions.

Although the rainfall partitionings in the KF, GR, BM and AK experiments are very different from each other in the simulation of the Mei-Yu front, Figs. $7 \mathrm{~d}$ and $8 \mathrm{~d}$ show that the ratios of parameterized to total precipitation remain approximately the same as the grid size decreases from $45 \mathrm{~km}$ to $15 \mathrm{~km}$ in each experiment. This suggests that the characteristics of these CPSs, although very different from each other, are relatively insensitive to mesoscale grid resolutions ranging between $10 \mathrm{~km}$ and $50 \mathrm{~km}$. Similar findings are reported in Kuo et al. (1996) for an oceanic cyclogenesis case and in Wang and Seaman (1997) for six precipitation events over the United States.

\section{c. Sounding verification}

Figure 9 shows the observed sounding of 0000 UTC 5 June 1998 on Dongsha Island where all cumulus experiments produce some precipitation. Figure 10 is the corresponding model soundings for various cumulus parameterization experiments on the $15-\mathrm{km}$ grid. Comparing Figs. 9 and 10, it is clear that the soundings produced by both the BM and GR experiments simulate the vertical profiles of temperature and moisture quite well; the KF experiment is the second best, but, in con rast, the sounding profile in the AK experiment is too moist and too unstable. To be specific, the sounding profile in the BM experiment (Fig. 10a) is conditionally unstable at the low levels. Its structure follows the reference sounding used in the Betts-Miller scheme that assumes an equilibrium in which weak convective instability is balanced by water loading. The GR experiment (Fig. 10b) also displays a conditionally unstable atmosphere below $800 \mathrm{hPa}$. The $\mathrm{KF}$ experiment (Fig. 10c) produces a near moist-neutral sounding above $700 \mathrm{hPa}$, with very little convective available potential energy (CAPE) for an air parcel lifted above $900 \mathrm{hPa}$. The sounding in the AK experiment is extremely unstable (Fig. 10d); an air parcel lifted from $1000 \mathrm{hPa}$ remains positively buoyant all the way to the top of the troposphere. Such a sounding cannot exist in a precipitating environment, but it is possible in the AK experiment because the parameterized precipitation in the Anthes-Kuo scheme is not dictated by the amount of CAPE but rather by the grid-scale moisture convergence (Kuo et al., 1996). Therefore, there is no guarantee that the Anthes-Kuo scheme eliminates the CAPE. Also, the specified parabolic heating profile in the Anthes-Kuo scheme does not necessarily lead to a moist neutral sounding even if there is a significant amount of precipitation.

\section{MICROPHYSICS EXPERIMENT}

Based on high-resolution cloud-model simulations for an intense midlatitude squall line, Yang and Houze (1995) indicate that hydrometeor types and ice-phase microphysical processes can significantly affect rainfall distribution, amount, and internal mesoscale structure 


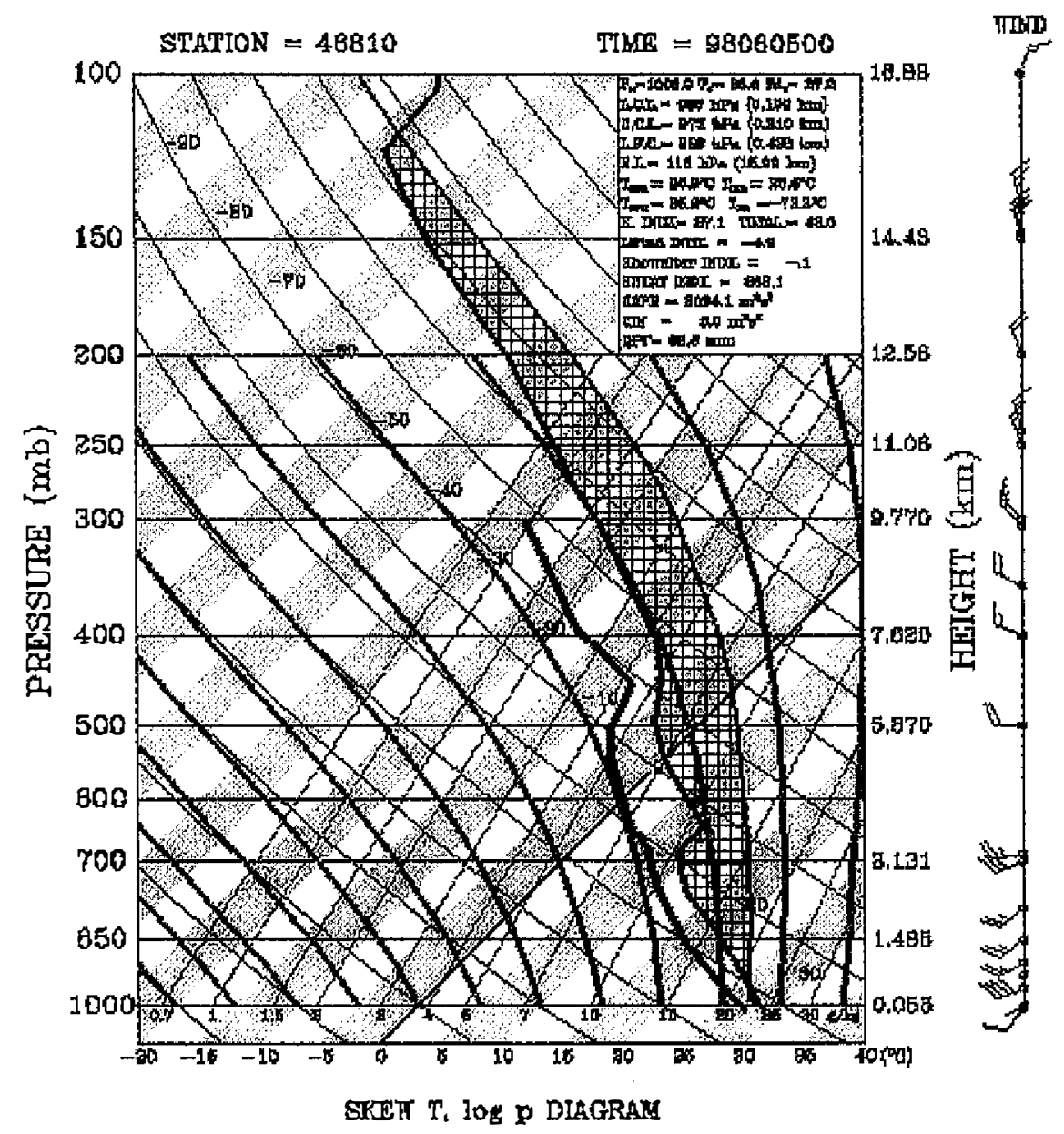

Fig. 9. Observed sounding of Dongsha Island (location shown in Fig. 4) at 0000 UTC 5 June 1998. Heavy line, temperature; light line, dewpoint. Coordinates: thin lines, temperature and pressure, dotted lines, dry adiabats; dashed lines, moist adiabats (curved) and saturation mixing ratio (straight).

within a precipitation system. Therefore, another important factor to determine simulated precipitation is the resolvable-scale microphysics parameterization scheme. In this set of sensitivity experiments the Kain-Fritsch scheme is used for cumulus parameterization on both the $45-\mathrm{km}$ and $15-\mathrm{km}$ grids. Figure 11 shows the 6-h accumulated total (parameterized and resolved) rainfall (1800 UTC 4 June to 0000 UTC 5 June 1998) on the $45-\mathrm{km}$ grid predicted by each microphysics run. Figure 12 is the corresponding precipitation forecast on the $15-\mathrm{km}$ grid. It is clear from Figs. 11 and 12 that the predicted rainfall distribution by each microphysical experiment is very similar on both the $45-\mathrm{km}$ and $15-\mathrm{km}$ grids.

Figures 13 and 14 show the domain-average precipitation and its partition for this set of experiments on the $45-\mathrm{km}$ grid and $15-\mathrm{km}$ grid, respectively. The Warm Rain (WR) experi- 
a) Betts-Miller

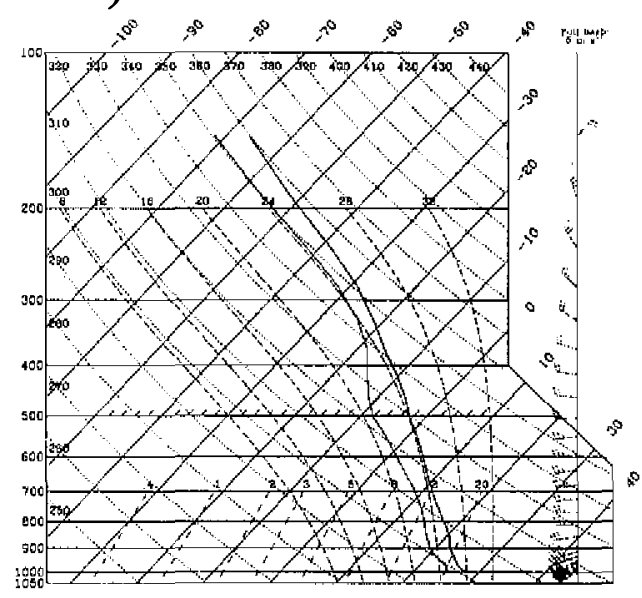

c) Kain-Fritsch

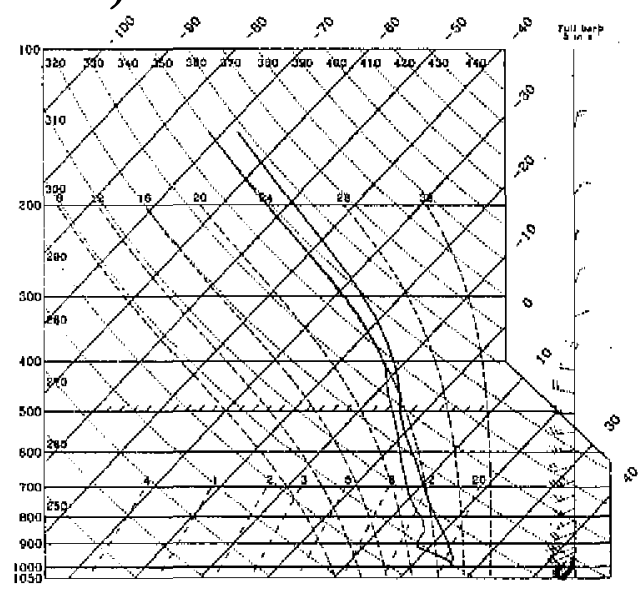

b) Grell

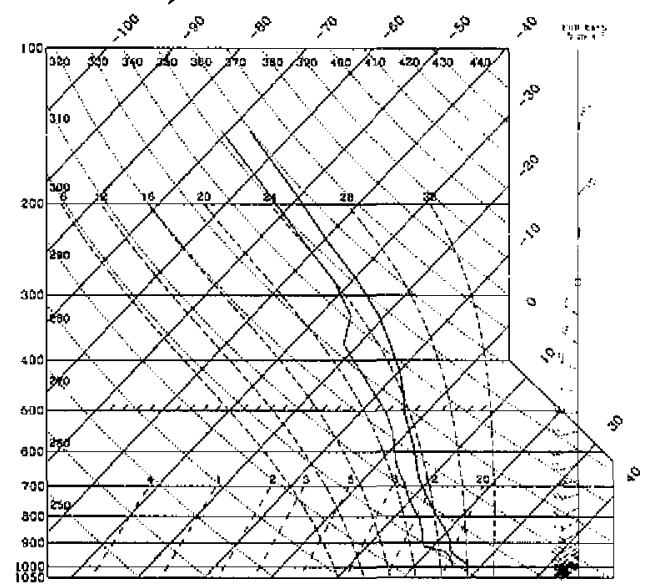

d) Anthes-Kuo

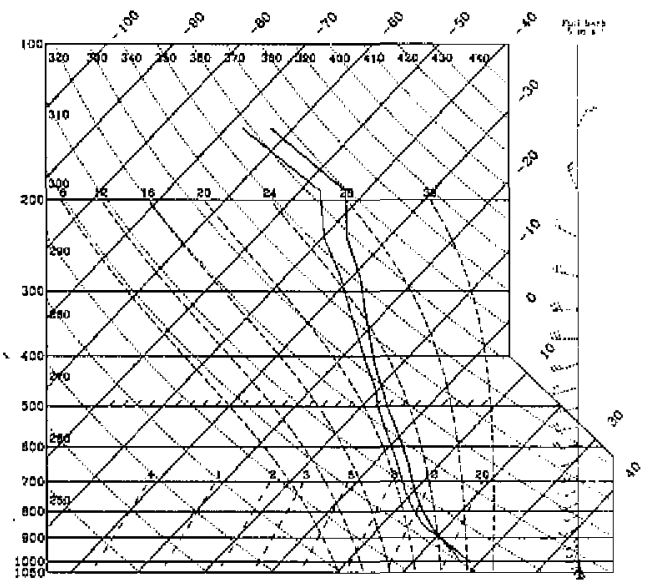

Fig. 10. Simulated sounding of Dongsha Island (location shown in Fig. 4) at 0000 UTC 5 June 1998 for the (a) Betts-Miller, (b) Grell, (c) Kain-Fritsch, and (d) Anthes-Kuo schemes. Heavy line, temperature; light line, dewpoint. Coordinates: thin lines, temperature and pressure, dotted lines, dry adiabats; dashed lines, moist adiabats (curved) and saturation mixing ratio (straight).

ment (Hsie et al., 1984), with the inclusion of warm rain (condensation and evaporation) processes only, produces the least precipitation. The Mixed Phase (MP) experiment (Reisner et al., 1998) produces slightly more rainfall than the WR experiment. This result indicates that the ice physics in the Mixed Phase scheme contributes positively to rainfall because the lower saturation vapor pressure over ice than over water allows for the condensation of water vapor 
a) Mixed Phase

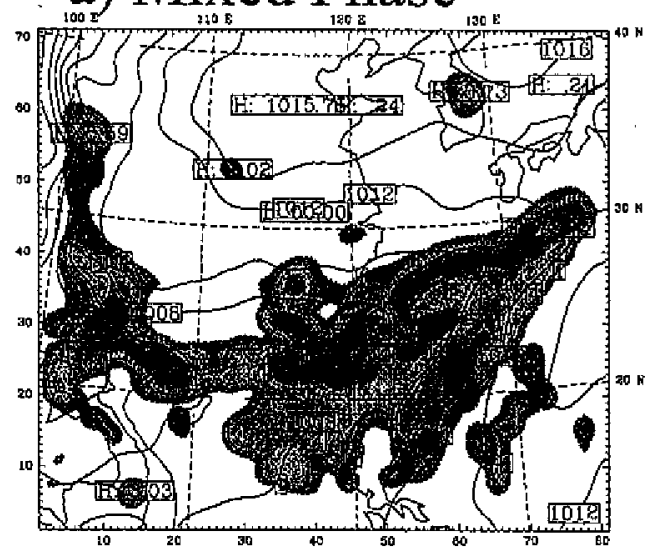

c) Simple Ice

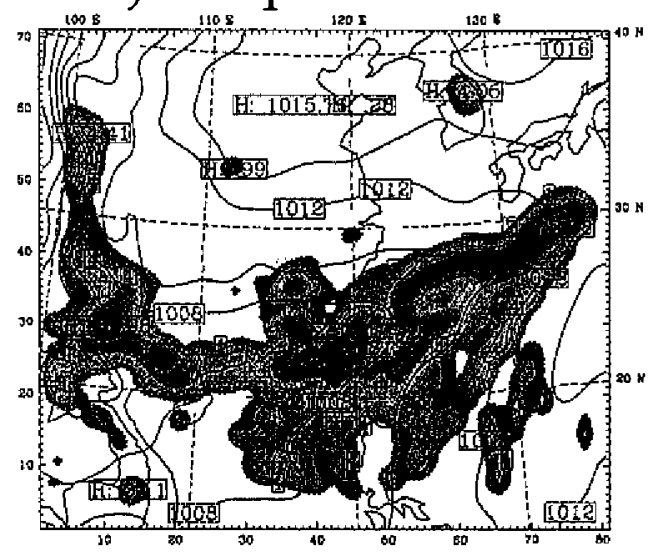

b) Goddard Graupel

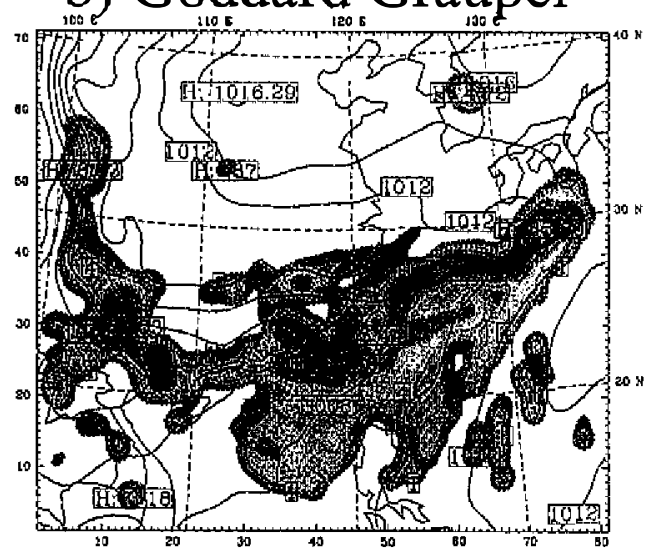

d) Warm Rain

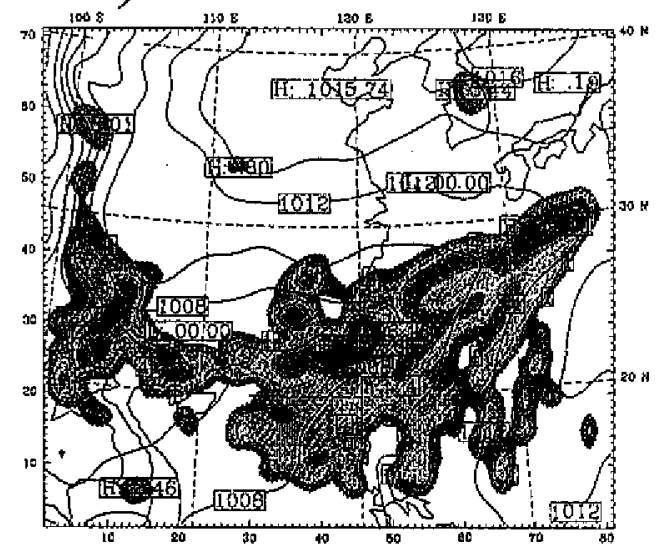

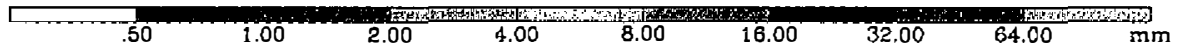

Fig. 11. Simulated sea-level pressure with contours of $2 \mathrm{hPa}$ for different microphysics parameterizations on the $45-\mathrm{km}$ grid at 24 -h forecast time (valid at 0000 UTC 5 June 1998): (a) Mixed Phase, (b) Goddard Graupel, (c) Simple Ice, and (d) Warm Rain scheme. Shading indicates 6-hourly (1800 UTC 4 June to 0000 UTC 5 June) accumulated rainfall in units of $\mathrm{mm}$.

at subfreezing temperature when cloud ice is included. The Simple Ice (SI) experiment (Dudhia 1989) produces precipitation amounts slightly greater than the MP experiment, but the difference is very small since the physical processes between the two schemes (Simple Ice and Mixed Phase) are similar despite the inclusion of supercooled liquid water in the Mixed Phase scheme. This suggests that the inclusion of supercooled liquid water effects in the resolvablescale microphysics scheme does not contribute significantly to surface precipitation for a 45$\mathrm{km} / 15-\mathrm{km}$ grid. Finally, the comparison between the Simple Ice and Goddard Graupel (GG) 
a) Mixed Phase

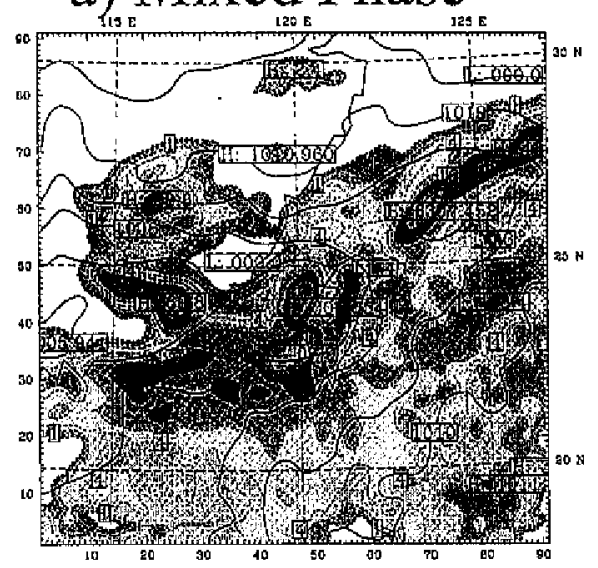

c) Simple Ice

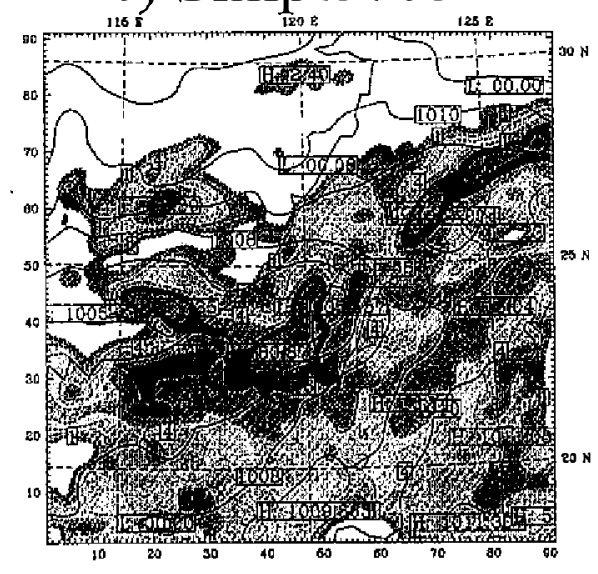

b) Goddard Graupel

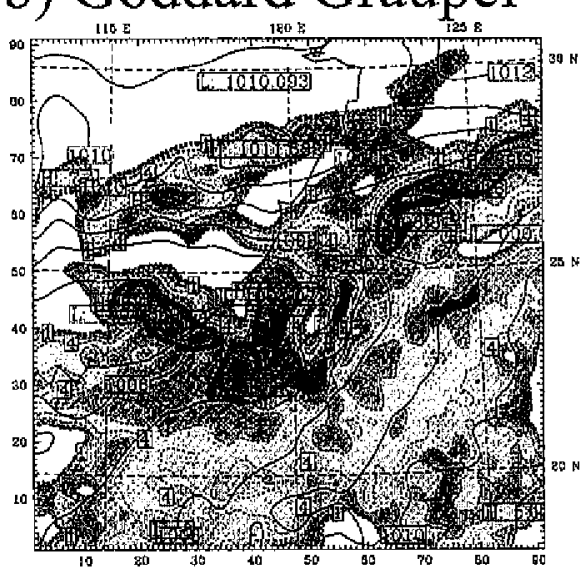

d) Warm Rain

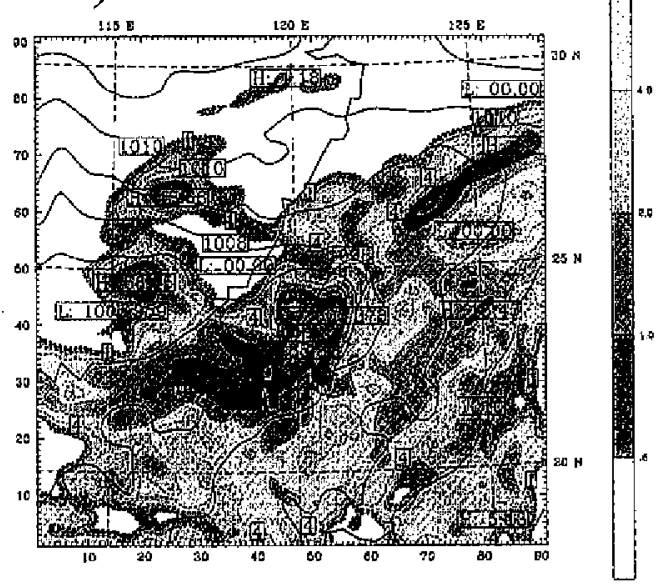

Fig. 12. Simulated sea-level pressure with contours of $1 \mathrm{hPa}$ for different microphysics parameterizations on the $15-\mathrm{km}$ grid at $24-\mathrm{h}$ forecast time (valid at 0000 UTC 5 June 1998): (a) Mixed Phase, (b) Goddard Graupel, (c) Simple Ice, and (d) Warm Rain scheme. Shading indicates 6-hourly (1800 UTC 4 June to 0000 UTC 5 June) accumulated rainfall in units of $\mathrm{mm}$.

experiments shows that the inclusion of graupel-type ice microphysics (Tao and Simpson 1993) produces $10-15 \%$ more surface precipitation throughout the period of the simulations (36 hours). In other words, the inclusion of cloud ice-snow-graupel microphysical processes increases the surface precipitation amount by $30 \%$ compared to the amount with only warm rain processes.

The results from the comparison are similar to the findings of McCumber et al. (1991), which indicate that the inclusion of ice-phase microphysical processes increases the modelpredicted rainfall amount and improves the simulation results. Based on sensitivity experi- 
a) Total Rain

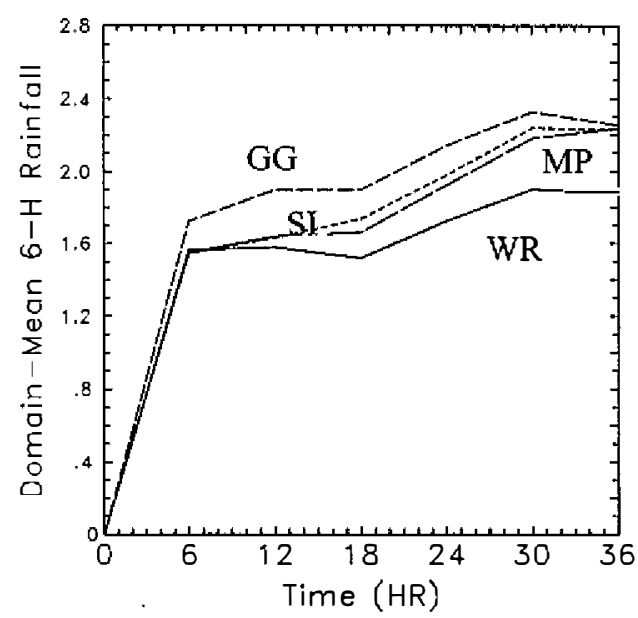

c) Resolved Rain

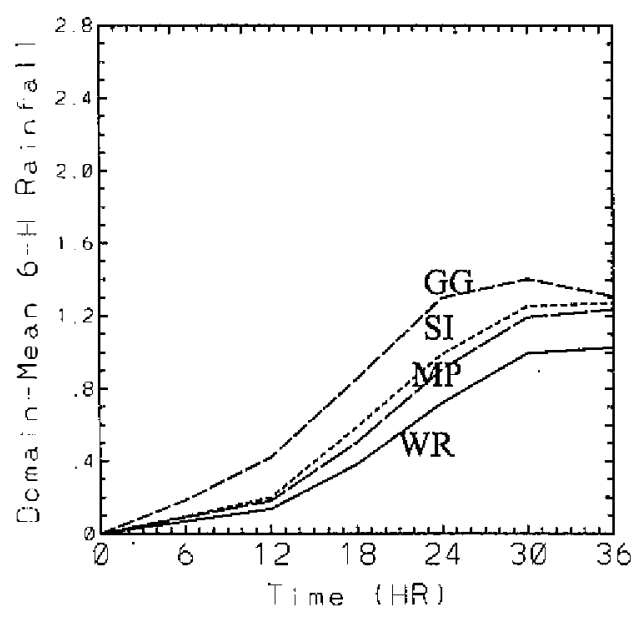

b) Parameterized Rain

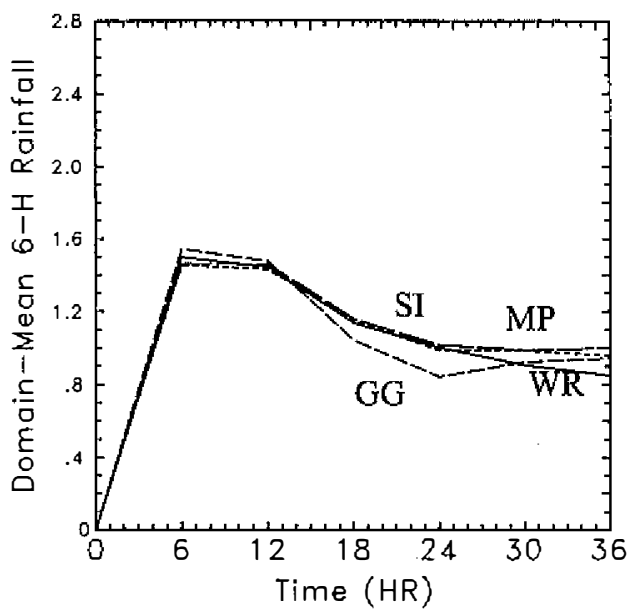

d) Parameterization Ratio

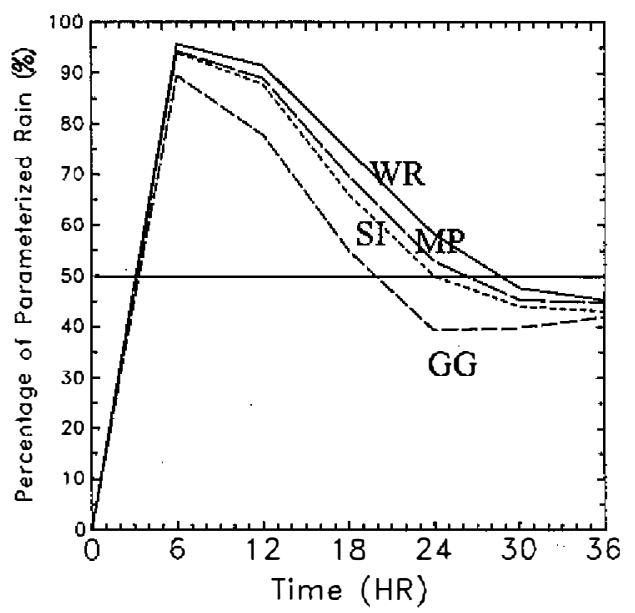

Fig. 13. (a) Domain-averaged 6-hourly total rainfall (in $\mathrm{mm}$ ), (b) domain-averaged parameterized rainfall (in $\mathrm{mm}$ ), (c) domain-averaged resolved rainfall (in $\mathrm{mm}$ ), and (d) percentage of parameterized to total rainfall on the 45-km grid for the microphysics experiments. MP: Mixed Phase. GG: Goddard Graupel. SI: Simple Ice. WR: Warm Rain.

ments from cloud-resolving model simulations, McCumber et al. (1991) show that the optimal mix of bulk ice hydrometeors for tropical cloud cluster simulation is cloud ice-snow-graupel. This microphysics experiments on Mei-Yu frontal precipitation also show that the optimal mix of bulk ice hydrometeors is cloud ice-snow-graupel, similar to the findings of McCumber et al. (1991). 
a) Total Rain

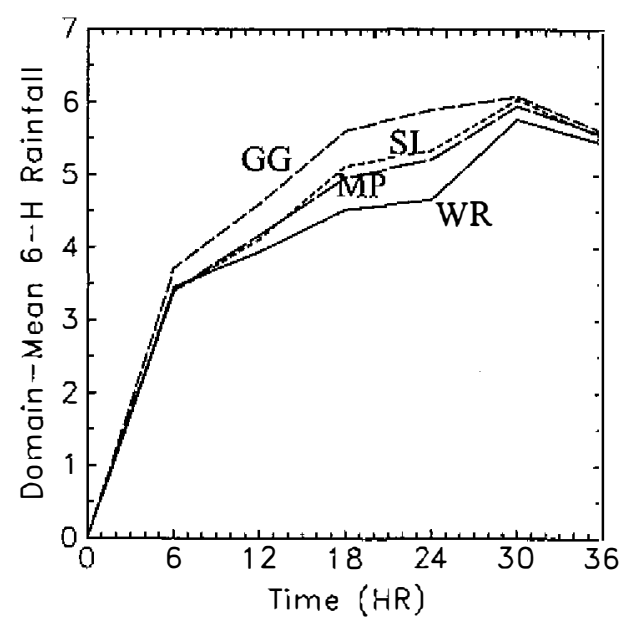

c) Resolved Rain

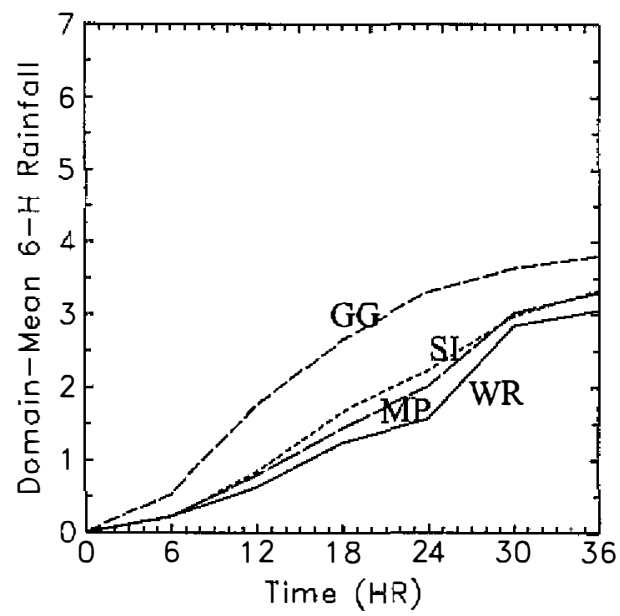

b) Parameterized Rain

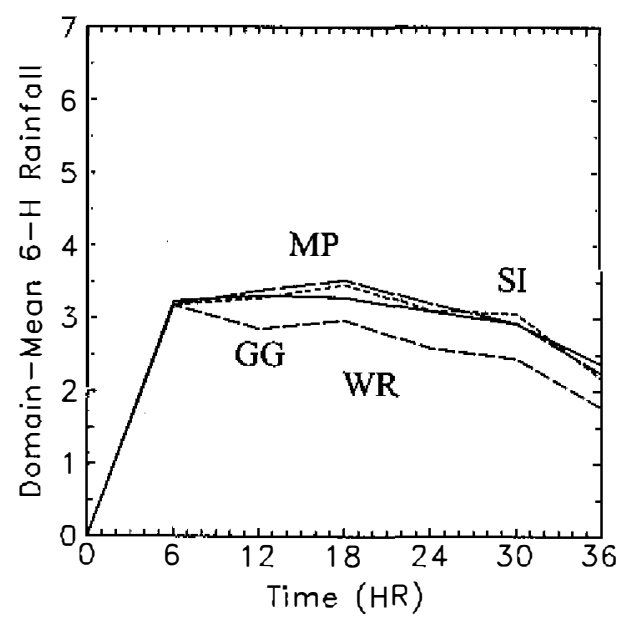

d) Parameterization Ratio

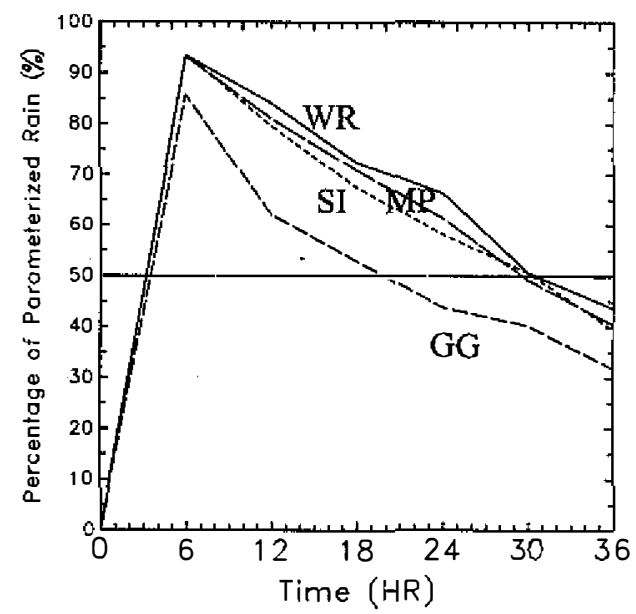

Fig. 14. (a) Domain-averaged 6-hourly total rainfall (in mm), (b) domain-averaged parameterized rainfall (in $\mathrm{mm}$ ), (c) domain-averaged resolved rainfall (in $\mathrm{mm}$ ), and (d) percentage of parameterized to total rainfall on the 15-km grid for the microphysics experiments. MP: Mixed Phase. GG: Goddard Graupel. SI: Simple Ice. WR: Warm Rain.

It is clear from Figs. $13 \mathrm{~b}$ and $14 \mathrm{~b}$ that parameterized precipitation is nearly the same in all experiments in this set. Evidently, subgrid-scale precipitation is little affected by the use of any particular resolvable-scale scheme. This is different from the results of the cumulus experiments (see Figs. 7b and 8b), in which it is noted that the same resolvable-scale microphysics scheme produces widely different precipitation amounts and distributions depending on 
the cumulus parameterization used. Apparently, variations in the subgrid-scale cumulus parameterization have a much larger impact on the distribution and amount of Mei-Yu frontal precipitation than do variations in the resolvable-scale microphysics parameterization at mesoscale grid resolutions of 10-50 km.

\section{CONCLUSIONS AND DISCUSSION}

With the increase in computational power, the separation of parameterized processes and grid-resolved processes in a numerical model becomes more obscure. Therefore, a systematic evaluation and the improvement in subgrid-scale parameterization across a wide range of grid sizes, particularly in the mesoscale modeling range of $10-50 \mathrm{~km}$, represent areas for further research.

Both the observational and modeling studies show that deep convection and its associated latent heat release within precipitating systems play important roles in the frontogenetical processes of a Mei-Yu front. Thus the proper treatment of convection and precipitation processes which are responsible for latent heat release is crucial for the success of a numerical simulation of a Mei-Yu front. However, a systematic evaluation of precipitation parameterizations in the simulation of a Mei-Yu front is rare in the literature.

In this paper, we conduct a series of numerical experiments on the 4-5 June $1998 \mathrm{Mei}-Y \mathrm{u}$ front with different combinations of precipitation physics and two different grid resolutions using the Penn State/NCAR nonhydrostatic mesoscale model MM5. The intent of this study is to identify the characteristic responses and systematic errors associated with mesoscale applications of the cumulus and microphysics schemes in the simulation of a Mei-Yu front. This information should be useful in the design of future numerical prediction systems and for the improvement in parameterization schemes for operational usage.

It should be noted that precipitation forecast errors do not solely result from a given cumulus scheme or a microphysics scheme; some errors may be the result of uncertainties in the model's initial conditions. Such details in initial conditions can be very important in obtaining a good precipitation forecast. Other errors may be related to deficiencies in model's internal components or to the coupling of precipitation schemes with other model physical parameterizations.

The first set of experiments utilizes a $45-\mathrm{km} / 15-\mathrm{km}$ nested grid with four different choices of cumulus parameterization. The simulated Mei-Yu fronts are similarly located among all cumulus experiments. However, the amounts and patterns of total precipitation (parameterized and resolved) as well as the partitioning of resolved and parameterized precipitation vary substantially. Apparently, the horizontal and vertical distributions of latent heating produced by different cumulus schemes affect the distribution and amount of frontal precipitation in a complicated, nonlinear manner.

The comparison of resolved and parameterized precipitation distribution at hour 24 in the simulations reveals a wide range of different behavior. All cumulus schemes develop prominent rainbands along the Mei-Yu front, but the type of precipitation (resolved versus parameterized) varies from almost all resolved (Grell scheme) to nearly all parameterized (AnthesKuo scheme). The domain-average total (resolved and parameterized) precipitation is roughly 
proportional to the factor increase in grid resolution.

For the same cumulus parameterization scheme, the ratio of parameterized to total rainfall changes very little as the grid resolution increases from $45 \mathrm{~km}$ to $15 \mathrm{~km}$. This is surprising because it might be expected that the resolvable-scale (or large scale) forcing and destabilization would change considerably with any reduction in grid size. The similarity in the gross precipitation characteristics at different grid sizes for the same cumulus scheme indicates that the fundamental closure assumption used in each cumulus scheme has a more profound influence on the behavior of the scheme than does the dependence of the grid-scale (or large scale) forcing on the grid size.

The examination of model soundings on Dongsha Island where all cumulus schemes produce some precipitation reveals significant differences in vertical stability. The simulated sounding produced by the Anthes-Kuo experiment is highly unstable to moist ascent, possessing substantial amounts of CAPE. Such unstable sounding is unrealistic and cannot be observed in the real atmosphere. Its occurance indicates the inefficiency of the Anthes-Kuo scheme in responding to the large-scale destabilization processes and in consuming the CAPE appropriately. The Grell experiment yields a similar structure although its sounding is not as unstable. The soundings produced by the Kain-Fritsch and Betts-Miller experiments have little, if any, CAPE. These two cumulus schemes respond promptly to large-scale destabilization processes and are highly effective in eliminating convective instability and resulting in little CAPE.

The second set of microphysics experiments on the $45-\mathrm{km} / 15-\mathrm{km}$ nested grid reveals that the precipitation pattern of the Mei-Yu front is little affected by the microphysics schemes employed. The addition of ice-phase microphysics results in a modest increase in the amount of precipitation. A refinement in ice-phase microphysics from the inclusion of supercooled liquid water produces a similar amount of surface precipitation, compared to that without mixphased processes. To the next level of complexity, the inclusion of graupel microphysical processes increases surface precipitation $10-15 \%$ further, or the inclusion of cloud ice-snowgraupel microphysics increases surface rainfall by $30 \%$ compared to that with only warm rain processes. Therefore, it is found that some level of ice-phase microphysics processes is required to produce a quantitative precipitation forecast with a reasonable degree of accuracy in a $45-\mathrm{km} / 15-\mathrm{km}$ mesoscale model. However, further improvement can be made with the consideration of more detailed ice-phase processes. Nevertheless, one would expect that as the grid resolution increases further (grid size of $5 \mathrm{~km}$ or less), the detailed ice-phase microphysical processes would have a stronger impact on the precipitation distribution and amount.

The comparison of these two sets of sensitivity experiments clearly shows that subgridscale cumulus parameterization has a much more profound influence on the precipitation distribution than does the resolvable-scale microphysics parameterization on the $45-\mathrm{km} / 15-\mathrm{km}$ grids. This finding can be explained by the fact that cumulus parameterization, through its redistribution of heat and moisture, can significantly affect the resolvable-scale temperature, moisture and vertical motion fields. Thus, it affects the intensity of latent heating and its horizontal and vertical distribution of precipitation. On the other hand, the functioning of a cumulus parameterization is only weakly sensitive to changes in the cloud microphysics on the resolvable scale. The two main factors determining the effectiveness of a cumulus param- 
eterization are the large-scale destabilization and the closure assumptions used in the scheme. Cloud microphysics on the resolvable scale has little effect on these two factors.

Considerable effort has been devoted to the study of convection and its representation in numerical models over the past 30 years (Emanuel and Raymond 1993). However, no general theory of cumulus parameterization is available (Arakawa 1993). No single scheme has been proven to work effectively and perfectly across a range of grid sizes and across a wide range of weather systems from mesoscale convective systems to typhoons, tropical cloud clusters and Mei-Yu fronts. This problem becomes even more complicated in a numerical model at grid resolutions of $10-50 \mathrm{~km}$ when a mesoscale precipitating system is partly resolved and partly parameterized (Molinari and Dudek 1992). Finally, much work remains to be done to understand how cumulus and microphysics parameterizations interact with other components of a model, especially in the mesoscale grid resolutions of $10-50 \mathrm{~km}$. Improvements in the model's initial conditions through three-dimensional or four-dimensional data assimilation techniques are also crucial so as to reduce errors in precipitation forecasts.

Acknowledgements The authors express their appreciation to Dr. Ying-Hwa Kuo who made the Penn State/NCAR MM5 model available for them to use. Gratitude is warmly extended to the late Dr. Shang-Wu Li for his effort in making Central Weather Bureau Global Model data accessible by MM5, Miss Yea-Ching Tung for her assistance with simulation execution, Miss Hui-Chuan Lin for archiving model and observation data and Dr. Jing-Shan Hong for sounding data. Satellite imagery and rain gauge data were provided by the Central Weather Bureau. Insightful discussions among scientists and weather forecasters during the Mei-Yu Experiment 1998 (MYEX 98) and South China Sea Monsoon Experiment (SCSMEX) were the inspiration for this study. The authors would like to thank reviewers for their constructive criticism which improved this paper substantially. This study started when the first author was affiliated with the Central Weather Bureau. Computation was performed on the Cray YMP computer at the Central Weather Bureau. This work was partially supported by National Science Council Grants NSC 87-2111-M-052-005 and NSC 88-2111-M-052-004AP6.

\section{APPENDIX A}

\section{A Brief Review of Cumulus Parameterization Schemes}

Here a brief description of each cumulus parameterization scheme (CPS) tested in this study is presented. Details of the CPS formulations appear in the referenced papers.

\section{a. Kuo scheme}

The Kuo scheme tested is a variation (Anthes-Kuo scheme; Anthes 1977) of the original Kuo scheme (Kuo 1974). This scheme uses the column-integrated moisture convergence $M_{t}$ to determine where convection occurs and how intense it is. Convection is initiated when conditional instability exists (determined by the parcel theory) and $M_{t}$ exceeds a threshold 
value $M_{t 0}\left(3 \times 10^{-5} \mathrm{~kg} \mathrm{~m}^{-2} \mathrm{~s}^{-1}\right)$ in the column. Then the moisture convergence is partitioned into the moistening of the column and parameterized precipitation, such that the precipitation PR is defined as:

$$
\mathrm{PR}=(1-b) M_{\imath} \text {, }
$$

where $b=2(1-<\mathrm{RH}>)$ and $<\mathrm{RH}>$ is the mean relative humidity of the grid column. This scheme does not include a cloud model nor parameterized convective downdrafts.

\section{b. Grell scheme}

The Grell scheme (1993) is a one-cloud version of the Arakawa-Schubert scheme (1974) with parameterized downdrafts, and it was first applied in the Penn State/NCAR mesoscale model. The closure used by the Grell scheme is the quasi-equilibrium assumption, as proposed by Arakawa and Schubert (1974). The subgrid precipitation PR is calculated as:

$$
\mathrm{PR}=I_{1} m_{b}(1-\beta),
$$

where $I_{l}$ is the integrated condensate in the updraft, $m_{b}$ is the cloud-based mass flux of the updraft, and $(1-\beta)$ is the precipitation efficiency, which is assumed to be a function of the mean wind shear in the lower troposphere. The effects of the convective-scale downdrafts (Cheng and Arakawa 1990) are parameterized in this scheme.

\section{c. Kain-Fritsch scheme}

The Kain-Fritsch scheme (Kain and Fritsch 1993) is similar to the Fritsch-Chappell scheme (1980), but with improvements made in the detrainment effect and cloud model. It was also first applied in the Penn State/NCAR mesoscale model. The closure assumption in the KainFritsch parameterization is the same as that used in the Fritsch-Chappell scheme. The convection is determined by the convective available potential energy (CAPE) on a grid point. Once convection is triggered, the CAPE is assumed to be removed in a grid column within an advective time period (roughly $30 \mathrm{~min}$ ). The Kain-Fritsch scheme utilizes an improved cloud model, which is mass-conservative, allows cloud-environment interaction, includes parameterized moist downdrafts and which has a detailed representation of cloud physics, including entrainment and detrainment across the cloud edge. The parameterized precipitation PR is computed as:

$$
\mathrm{PR}=E S,
$$

where $E$ is the precipitation efficiency, and $S$ is the sum of the vertical fluxes of vapor and liquid at about $150 \mathrm{hPa}$ above the lifting condensation level (LCL). 


\section{d. Betts-Miller scheme}

This version of Betts-Miller scheme (Betts and Miller 1993) is similar to that currently used in the operational eta model (Janjic 1994) at the National Center for Environmental Prediction (NCEP). Unlike the other three CPSs, the Betts-Miller scheme is a lagged convective adjustment scheme. It adjusts the model's thermal and moisture structure toward specified reference profiles that represent the quasi-equilibrium state established by deep convection (Betts 1986). The parameterized precipitation PR resulting from this adjustment is defined as:

$$
\mathrm{PR}=\int_{p_{B}}^{p_{\tau}} \frac{q_{R}-q}{\tau} \frac{d p}{g}
$$

where $q$ is the model's specific humidity, $q_{R}$ is the reference profile specific humidity (a function of height), $\tau$ is the time scale for which the adjustment occurs, and $p_{T}$ and $p_{B}$ are pressures at cloud top and bottom, respectively. The parameters used to specify the temperature and moisture profiles and the adjustment time scale are the same as those used by the NCEP eta model, which may or may not be applicable to Mei-Yu frontal precipitation.

\section{APPENDIX B}

\section{A Brief Review of Microphysics Parameterization Schemes}

Here each microphysics parameterization scheme tested in this study is briefly described. Details of the parameterization formulations appear in the referenced papers.

\section{a. Warm Rain scheme}

This Warm Rain scheme is described in Hsie et al. (1984), and it basically considers the warm-rain processes as first discussed in Kessler (1969). In this scheme, prognostic equations are included for water vapor, cloud water and rain water. Evaporation in unsaturated layers is included.

\section{b. Simple Ice scheme}

This Simple Ice scheme was developed by Dudhia (1989) and it considers warm cloud processes below and cold cloud processes above the freezing level. Instantaneous freezing and melting take place at the $0^{\circ} \mathrm{C}$ level. No supercooled liquid water is allowed above the melting level. In other words, only a simplified treatment of ice microphysical processes is considered. 


\section{c. Mixed Phase scheme}

The Mixed Phase scheme was developed by Reisner et al. (1998) and this scheme uses five prognostic equations for water vapor, cloud water, rain water, cloud ice and snow. Because the scheme allows for the coexistence of liquid water and ice above the freezing level, the effect of supercooled liquid water is taken into consideration.

\section{d. Goddard Graupel scheme}

The Goddard Graupel scheme was developed by Tao and Simpson (1993) and it includes six classes of water substance, especially graupel. The addition of graupel permits an even more complete treatment of the precipitation processes.

\section{REFERENCES}

Akiyama, T., 1973: The large-scale aspects of the characteristic features of Baiu front. Pap. Meteor. Geophys., 24, 157-188.

Anthes, R. A., 1977: A cumulus parameterization scheme utilizing a one-dimensional cloud model. Mon. Wea. Rev., 105, 270-286.

Arakawa, A., 1993: Closure assumptions in the cumulus parameterization problem. The Representation of Cumulus Convection in Numerical Models, Meteor. Monger., No. 46, Amer. Meteor. Soc., 1-15.

Arakawa, A., and W. H. Schubert, 1974: Interaction of a cumulus cloud ensemble with the large-scale environment. Part I. J. Atmos. Sci., 31, 674-701.

Betts, A. K., 1986: A new convective adjustment scheme. Part I: Observational and theoretical basis. J. Roy. Meteor. Soc., 112, 677-692.

Betts, A. K., and M. J. Miller, 1986: A new convective adjustment scheme. Part II: Single column tests using GATE wave, BOMEX, ATEX, and Arctic air-mass data. Quart. J. Roy. Meteor. Soc., 112, 693-709.

Betts, A, K., and M. J. Miller, 1993: The Betts-Miller scheme. The Representation of Cumulus Convection in Numerical Models, Meteor. Monogr. No. 46, Amer. Meter Soc., 107-121.

Blackadar, A. K., 1979: High resolution models of the planetary boundary layer. Advances in Environmental Sciences and Engineering. Vol. 1, Pfafflin and Ziegler, Eds, Gordon and Breach, 50-85.

Chen, G. T.-J.,1977: An analysis of moisture structure and rainfall for a Mei-Yu regime in Taiwan. Proc. Natl. Sci. Counc., Taipei, 11, 1-21.

Chen, G. T.-J., 1983: Observational aspects of the Mei-Yu phenomena in subtropical China. J. Meteor. Soc. Japan, 61, 306-312.

Chen, G. T.-J., 1995: An overview of the heavy rainfall research in the Taiwan Mei-Yu season. Preprints, The Workshop on Mesoscale Meteorology and Heavy Rain in East Asia, Nov. 7-10, 1995, Fuzhou, China, 2-7. 
Chen, G. T.-J., and C.-P. Chang, 1980: The structure and vorticity budget of an early summer monsoon (Mei-Yu) over southeastem China and Japan. Mon. Wea. Rev., 108, 942-953.

Chen, G. T.-J., and S. S. Chi, 1980: On the frequency and speed of Mei-Yu front over southern China and the adjacent areas. Pap. Meteor. Res., 3, 31-42.

Chen, G. T.-J., and C.-C. Yu, 1988: Study of low-level jet and extremely heavy rainfall over northern Taiwan during the Mei-Yu season. Mon. Wea. Rev., 116, 884-891.

Chen, Y.-L., 1993: Some synoptic-scale aspects of the surface fronts over southern China during TAMEX. Mon. Wea. Rev., 121, 50-64.

Chen, Y.-L., and N. B.-F. Hui, 1992: Analysis of a relatively dry front during the Taiwan Area Mesoscale Experiment. Mon. Wea. Rev., 120, 2442-2468.

Chen, Y.-L., Y.-X. Zhang, and N. B.-F. Hui, 1989: Analysis of a surface front during the early summer rainy season over Taiwan. Mon. Wea. Rev., 117, 909-931.

Cheng, M.-D., and A. Arakawa, 1990: Inclusion of convective downdrafts in the ArakawaSchubert cumulus parameterization. Tech. Rep., Dept. of Atmospheric Sciences, Univ. of California, Los Angeles, $69 \mathrm{pp}$.

Dudhia, J., 1989: Numerical study of convection observed during the winter monsoon experiment using a mesoscale two-dimensional model. J. Atmos. Sci., 46, 3077-3107.

Emanuel, K. A., and D. J. Raymond, (Eds.), 1993: The Representation of Cumulus Convection in Numerical Models. Meteor. Monogr., No. 46, Amer. Meteor. Soc., 246 pp.

Fritsch, J. M., and C. F. Chappell, 1980: Numerical prediction of a convectively driven mesoscale pressure system. Part I: Convective parameterization. J. Atmos. Sci., 37, 17221733.

Grell, G., 1993: Prognostic evaluation of assumptions used by cumulus parameterizations. Mon. Wea. Rev., 121, 764-787.

Grell, G., Y.-H. Kuo, and R. J. Pasch, 1991: Semiprognostic tests of cumulus parameterization schemes in the middle latitude. Mon.Wea. Rev., 119, 5-31.

Grell, G. A., J. Dudhia, and D. R. Stauffer, 1994: A description of the fifth generation Penn State/NCAR mesoscale model (MM5). NCAR Tech Note NCAR/TN-398+STR, 138 pp.

Hsie, E.-Y., R. A. Anthes, and D. Keyser, 1984: Numerical simulation of frontogenesis in a moist atmosphere. J. Atmos. Sci., 41, 2581-2594.

Hsu, W.-R., and W.-Y. Sun, 1994 A numerical study of a low-level jet and its accompanying secondary circulation in the Mei-Yu season. Mon. Wea. Rev., 122, 324-340.

Janjic, Z. I., 1994: The step-mountain eta coordinate model: Further developments of the convection, viscous sublayer, and turbulence closure schemes. Mon. Wea. Rev., 122, 927-945.

Kain, J. S., and J. M. Fritsch, 1993: Convective parameterization for mesoscale models: The Kain-Fritsch scheme. The Representation of Cumulus Convection in Numerical Models, Meteor. Monger., No. 46, Amer. Meteor. Soc., 165-177.

Kato, K., 1985: On the abrupt change in the structure of the Baiu front over the China continent in late May of 1979. J. Meteor. Soc. Japan, 63, 20-35.

Kessler, E., 1969: On the distribution and continuity of water substance in atmospheric circu- 
lations. Metoro. Monogr., 10, No. 32, 84 pp.

Kuo, H. L., 1974: Further studies of the parameterization of the influence of cumulus convection on large-scale flow. J. Atmos. Sci., 31, 1232-1240.

Kuo, Y.-H., and R. A. Anthes, 1982: Numerical simulation of a Mei-Yu system over southeastern Asia. Pap. Meteor. Res., 5, 15-36.

Kuo, Y.-H., and G. T.-J. Chen, 1990: The Taiwan Area Mesoscale Experiment (TAMEX): An overview. Bull. Amer. Meteor. Soc., 71, 488-503.

Kuo, Y.-H., R. J. Reed, and Y. Liu, 1996: The ERICA IOP 5 Storm. Part III: Mesoscale cyclogenesis and precipitation parameterization. Mon. Wea. Rev., 124, 1409-1434.

Liu, C.-S, J.-H. Chen, C.-T. Terng, F.-J. Wang, C.-T. Fong, T. E. Rosmond, H.-C. Kuo, C.-H. Shiao, and M.-D. Cheng, 1997: The second generation global forecast system at the Central Weather Bureau in Taiwan. Wea. Forecasting, 12, 653-663.

Matsumoto, S., K. Ninomiya, and S. Yoshizumi, 1971: Characteristic features of the 'Baiu' front associated with heavy rain. J. Meteor. Soc. Japan, 52, 300-313.

McCumber, M., W.-K. Tao, J. Simpson, R. Penc, and S.-T. Soong, 1991: Comparison of the ice-phase microphysical parameterization scheme using numerical simulation of tropical convection. J. Appl. Meteor., 30, 985-1004.

Molinari, J., and M. Dudek, 1992: Parameterization of convective precipitation in mesoscale models: A critical review. Mon. Wea. Rev., 120, 326-344.

Ninomiya, K., 1984: Characteristics of the Biau front as a predominant subtropical front in the summer northern hemisphere. J. Meteor. Soc. Japan, 62, 880-894.

Olson, D. A., N. W. Junker, and B. Korty, 1995: Evaluation of 33 years of quantitative precipitation forecasting at the NMC. Wea. Forecasting, 10, 498-511.

Reisner, J., R. T. Bruintjes, and R. J. Rasmussen, 1998: Explicit forecasting of supercooled water in winter storms using the MM5 mesoscale model. Quart. J. Roy. Meteor. Soc., 124B, 1071-1107.

Tao, W.-K., and J. Simpson, 1993: The Goddard cumulus ensemble model. Part I: Model description. TAO, 4, 35-72.

Wang, C. T.-C., Y.-J. Lin, R. W. Pasken, and H. Shen, 1990: Characteristics of a subtropical squall line determined from TAMEX dual-Doppler data. Part I: Kinematic structure. $J$. Atmos. Sci., 47, 2357-2381.

Wang, W., and N. L. Seaman, 1997: A comparison study of convective parameterization schemes in a mesoscale model. Mon. Wea. Rev., 125, 252-278.

Yang, M.-J., and R. A. Houze, Jr., 1995: Sensitivity of squall-line rear inflow to ice microphysics and environmental humidity. Mon. Wea. Rev., 123, 3175-3193.

Zhang, D.-L., K. Gao, and D. B. Parson, 1989: Numerical simulation of an intense squall line during 10-11 June 1985 PRE-STORM. Part I: Model verification. Mon.Wea. Rev., 117, 960-994. 